\title{
Selective recovery of a pyridine derivative from an aqueous waste stream containing acetic acid and succinonitrile with solvent impregnated resins.
}

\section{Citation for published version (APA):}

Bokhove, J., Visser, T. J., Schuur, B., \& Haan, de, A. B. (2014). Selective recovery of a pyridine derivative from an aqueous waste stream containing acetic acid and succinonitrile with solvent impregnated resins. Reactive and Functional Polymers, 87, 67-79. https://doi.org/10.1016/j.reactfunctpolym.2014.11.007

DOI:

10.1016/j.reactfunctpolym.2014.11.007

Document status and date:

Published: 01/01/2014

\section{Document Version:}

Publisher's PDF, also known as Version of Record (includes final page, issue and volume numbers)

\section{Please check the document version of this publication:}

- A submitted manuscript is the version of the article upon submission and before peer-review. There can be important differences between the submitted version and the official published version of record. People interested in the research are advised to contact the author for the final version of the publication, or visit the $\mathrm{DOI}$ to the publisher's website.

- The final author version and the galley proof are versions of the publication after peer review.

- The final published version features the final layout of the paper including the volume, issue and page numbers.

Link to publication

\footnotetext{
General rights

- You may freely distribute the URL identifying the publication in the public portal. follow below link for the End User Agreement:

www.tue.nl/taverne

\section{Take down policy}

If you believe that this document breaches copyright please contact us at:

openaccess@tue.nl

providing details and we will investigate your claim.
}

Copyright and moral rights for the publications made accessible in the public portal are retained by the authors and/or other copyright owners and it is a condition of accessing publications that users recognise and abide by the legal requirements associated with these rights.

- Users may download and print one copy of any publication from the public portal for the purpose of private study or research.

- You may not further distribute the material or use it for any profit-making activity or commercial gain

If the publication is distributed under the terms of Article $25 \mathrm{fa}$ of the Dutch Copyright Act, indicated by the "Taverne" license above, please 


\title{
Selective recovery of a pyridine derivative from an aqueous waste stream containing acetic acid and succinonitrile with solvent impregnated resins
}

\author{
J. Bokhove ${ }^{\text {a }}$, T.J. Visser ${ }^{\text {b }}$, B. Schuur ${ }^{\text {c,* }}$, A.B. de Haan ${ }^{\mathrm{d}}$

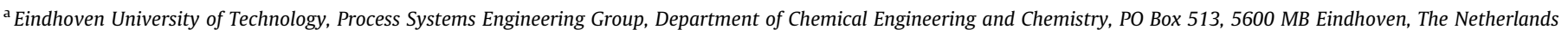 \\ ${ }^{\mathrm{b}}$ Syncom B.V. Kadijk 3, 9747 AT Groningen, The Netherlands \\ ${ }^{\mathrm{c}}$ University of Twente, Faculty of Science and Technology, Sustainable Process Technology Group, Green Energy Initiative, PO Box 217, 7500 AE Enschede, The Netherlands \\ ${ }^{\mathrm{d}}$ Faculty of Applied Sciences, Department of Chemical Engineering, Delft University of Technology, Julianalaan 136, 2628 BL Delft, The Netherlands
}

\section{A R T I C L E I N F O}

\section{Article history:}

Received 2 September 2014

Received in revised form 9 November 2014

Accepted 18 November 2014

Available online 3 December 2014

\section{Keywords:}

Solvent impregnated resin

Brominated phenol

Pyridine derivatives

Waste water treatment

Fixed bed

\begin{abstract}
A B S T R A C T
Solvent impregnated resins (SIRs) were evaluated for the recovery of pyridine derivatives from an aqueous waste-stream containing also acetic acid and succinonitrile. For this purpose, a new solvent was developed, synthesized and impregnated in Amberlite XAD4. Sorption studies were used to determine the capacity, selectivity and the mass-transfer rate. A high capacity of $21 \mathrm{~g} 4$-cyanopyridine (CP) per kg SIR was found, with very high selectivity toward CP over the other solutes of at least 570. A modified Langmuir equation could describe the equilibrium sorption isotherm. Both the linear driving force model and a Fickian diffusion model were evaluated. The Fick-model described both regeneration and loading best. The CP-diffusivity through the solvent phase was estimated at $6.53 \cdot 10^{-13} \pm 2.5 \%$ $\mathrm{m}^{2} \mathrm{~s}^{-1}$. The model was validated using fixed-bed column experiments. The $R^{2}$ values for this model ranged between 0.94 at a flow rate of $5 \mathrm{~mL} / \mathrm{min}$ and 0.99 at a flow rate of $1 \mathrm{~mL} / \mathrm{min}$ during the loading cycle. Due to mass-transfer limitations the breakthrough profiles were broad and breakthrough occurred after 5 or 23 bed volumes, for flow rates of 5 and $1 \mathrm{~mL} / \mathrm{min}$, respectively. Both acetic acid and succinonitrile broke through immediately due to the very high CP-selectivity of the SIR.
\end{abstract}

(ㄷ) 2014 Elsevier B.V. All rights reserved.

\section{Introduction}

Trace removal involves the removal of impurities present in low concentrations from either waste-streams or product streams, and aims at preventing emission of toxic compounds or at product purification. The main issue in trace-removal is the high number of separation stages that are required to achieve the desired trace-compound(s) removal from the product stream. Typically outlet concentrations below $5 \mathrm{ppm}$ are desired and especially when large streams are to be purified, this could lead to large equipment if the separation is less efficient. Novel, highly efficient technologies are thus desired, and because traditional separation technologies like adsorption [1] and extraction [2] can both yield high capacities and selectivities, they suffer from drawbacks like difficult regeneration in the case of adsorption, and entrainment or irreversible emulsification in the case of extraction.

\footnotetext{
* Corresponding author.

E-mail addresses: Jeroen.Bokhove@gmail.com (J. Bokhove), t.visser@syncom.nl (T.J. Visser), b.schuur@utwente.nl (B. Schuur).
}

In this study, a promising alternative for these technologies, the solvent impregnated resin (SIR) [3] was evaluated for a specific case of wastewater treatment. The wastewater stream that is considered in this work consists of pyridine derivatives (e.g. 4-cyanopyridine, CP), nitriles (e.g. succinonitrile) and oxygenated compounds (e.g. acetic acid) that are typically formed in the production of cyanopyridine, acrylonitrile and pyridine [4-7]. The aim was to selectively remove the highly water soluble pyridine derivatives from this stream, since without precautions there is a chance that they might end up in the wastewater stream, resulting in highly diluted aqueous waste streams that are complex of nature. Due to the toxicity and poor biodegradability of some of these components, the treatment of such wastewater streams is of great environmental importance [4-7].

Using a SIR-based process $[3,8]$ for water purification is beneficial, because the solvent is immobilized in a macro-porous particle, and as a result, mixing and settling of the aqueous and organic phase are no longer required and entrainment and irreversible emulsification are prevented. In the literature, SIRs have been developed for the in-situ recovery of products from a fermentation 


\begin{tabular}{|c|c|c|c|}
\hline \multicolumn{4}{|c|}{ Nomenclature } \\
\hline \multicolumn{2}{|c|}{ Abbreviations } & $k_{\mathrm{f}}$ & aqueous phase resistance toward mass-transfer $\left[\mathrm{s}^{-1}\right]$ \\
\hline $\mathrm{CP}$ & 4-cyanopyridine & $K_{\mathrm{LDF}}$ & overall mass-transfer coefficient $\left[\mathrm{s}^{-1}\right]$ \\
\hline$(\mathrm{CP})_{n} \mathrm{DBP}$ & complex of 4-cyanopyridine with the reactive solvent & $K_{\mathrm{D}}$ & distribution coefficient $[-]$ \\
\hline $\mathrm{CPH}^{+}$ & protonated 4-cyanopyridine & $L$ & length of the column [m] \\
\hline DMF & dimethylformamide & $M_{\mathrm{w}, \mathrm{cp}}$ & molecular weight of 4 -cyanopyridine $\left[\mathrm{g} \mathrm{mole}^{-1}\right.$ ] \\
\hline DMS & dimethylsulfate & $n$ & stoichiometry [-] \\
\hline HAc & acetic acid & $q$ & loading of the SIR [ $\mathrm{g} \mathrm{CP} / \mathrm{kg}$ SIR] \\
\hline $\mathrm{H}^{+}$ & proton & $q_{\mathrm{s}, \text { tot }}$ & solvent loading of the SIR [mL solvent $/ \mathrm{kg}$ SIR] \\
\hline LDA & lithium diisopropylamide & $R$ & radius of the SIR $[\mathrm{m}]$ \\
\hline DBP & the reactive brominated phenol solvent & $r$ & radial position $[\mathrm{m}]$ \\
\hline SIR & solvent impregnated resin & $S$ & selectivity [-] \\
\hline SN & succinonitrile & $t$ & time $[s]$ \\
\hline $\operatorname{Re}$ & Reynolds & $\begin{array}{l}u \\
V\end{array}$ & $\begin{array}{l}\text { interstitial velocity }[\mathrm{m} / \mathrm{s}] \\
\text { volume }\left[\mathrm{m}^{3}\right]\end{array}$ \\
\hline Symbols & & $z$ & normalized position in the bed [-] \\
\hline$A$ & cross-sectional area of the column $\left[\mathrm{m}^{2}\right]$ & & \\
\hline$c$ & concentration $\left[\mathrm{g} \mathrm{m}^{-3}\right]$ & \multicolumn{2}{|c|}{ Subscripts } \\
\hline$C F$ & capacity factor $[\mathrm{L} / \mathrm{g}]$ & eq & equilibrium \\
\hline$D$ & effective diffusion coefficient $\left[\mathrm{m}^{2} \mathrm{~s}^{-1}\right]$ & org & organic phase \\
\hline$D_{\mathrm{ax}}$ & axial dispersion coefficient $\left[\mathrm{m}^{2} \mathrm{~s}^{-1}\right]$ & $\mathrm{aq}$ & aqueous phase \\
\hline$d_{\mathrm{p}}$ & diameter of the SIR [m] & bt & breakthrough \\
\hline$\varepsilon_{\mathrm{b}}$ & void fraction in the bed $[-]$ & & \\
\hline & void fraction in the resin $[-]$ & \multicolumn{2}{|c|}{ superscript } \\
\hline$K_{\mathrm{c}}^{\mathrm{app}}$ & apparent complexation strength $\left[\left(\mathrm{L} \mathrm{mole}^{-1}\right)^{1-n}\right]$ & $\mathrm{t}$ & time \\
\hline$K_{\mathrm{a}}$ & dissociation constant $\left[\mathrm{L} \mathrm{mole}^{-1}\right]$ & & \\
\hline
\end{tabular}

broth [9], the recovery of caprolactam from water [10] and the removal of several other polar organic compounds from water [11-17]. The drawback of this technology is that leaching of solvent may result in a fast depletion of the capacity [18], which should be minimized by selecting a solvent with a low solubility in water and a high affinity for the resin.

In our previous study a solvent selection procedure was presented for the selective removal of $\mathrm{CP}$ from an aqueous phase [19]. In that study, it was found that with phenol based solvents the highest capacities were obtained, whereas 4-nonylphenol has a very low solubility (5 ppm) [20] in the aqueous phase, which is beneficial for SIR processes. By impregnating 4-nonylphenol in Amberlite XAD4, a resin consisting of polystyrene cross-linked with divinylbenzene, a highly stable SIR was obtained [21]. The regeneration could be performed by a $\mathrm{pH}$-swing with hydrochloric acid at a $\mathrm{pH}$ of 1 , where the concentration of $\mathrm{CP}$ could be increased from $0.5 \mathrm{~g} / \mathrm{L}$ in the loading cycle as feed solution to a maximum of $3 \mathrm{~g} / \mathrm{L}$ in the effluent during the regeneration cycle. However, the capacity of the SIR containing 4-nonylphenol was limited, and for this reason a modified phenol with a higher capacity for the target compound was developed and custom-synthesized. The designed solvent, consisting of a 1:1 mixture (mole basis) of 3,5-dibromo4-(4,6,6-trimethylheptyl)phenol and 3,5,-dibromo-4-(4,8-dimethylnonyl)phenol is presented in Fig. 1. The solvent (abbreviated by DBP) is a mixture of two molecules varying in their alkyl chain to reduce the viscosity.

After validating the high capacity of $43 \mathrm{~g} \mathrm{CP} / \mathrm{kg}$ SIR [19], the aim of the here presented study was to characterize the performance of a SIR consisting of Amberlite XAD4 resins impregnated with the brominated solvent for the selective recovery of $\mathrm{CP}$ from a mixture of acetic acid (HAc) and succinonitrile (SN), the molecular structures of the solutes are given in Fig. 2.

Elements of the study to characterize the performance of the SIR include the development of a thermodynamic model to describe the capacity, a mass-transfer model to evaluate the mass-transfer rate and a fixed bed model to evaluate the breakthrough profiles during the loading of a column and the effluent concentration during the regeneration of the column. The models were validated with experimental fixed-bed column data. Finally, the evaluated model was used to perform process-simulations to determine the<smiles>CC(CCCc1c(Br)cc(O)cc1Br)CC(C)(C)C</smiles><smiles>CC(C)CCCC(C)CCCc1c(Br)cc(O)cc1Br</smiles>

Fig. 1. Molecular structure of the solvent, consisting of a 1:1 mixture of two alkylated dibromophenols. 


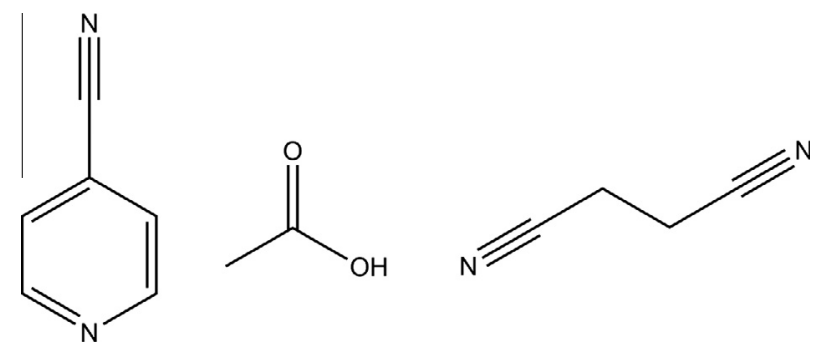

Fig. 2. Molecular structures of the solutes: 4-cyanoypridine, acetic acid and succinonitrile.

length of the mass-transfer zone and to study the radial concentration profiles inside the SIR during regeneration.

\section{Theory}

In the following section the model that was developed in this study is discussed. There are 3 main elements in the model as presented in Fig. 3:

- The thermodynamic liquid-liquid equilibrium model, describing the concentrations of the species in the impregnated organic solvent phase at equilibrium with the bulk aqueous phase composition.

- The mass-transfer model, describing the diffusion through the organic phase in the pores of the resin.

- The fixed-bed model, describing the axial concentration gradients in the bed.

\subsection{Thermodynamic model}

The thermodynamic equilibrium of the extraction with a solvent impregnated resin can be described using an adsorption isotherm including the interactions in the solvent phase. The interactions included in the equilibrium isotherm are the hydrogen bonding interactions between $\mathrm{CP}$ and the phenol based solvent. Here, both nitrogen atoms of $\mathrm{CP}$ act as Lewis base and the hydroxyl functional group of DBP acts as Lewis acid [22]. In a previous study [23], we established a model describing interactions of the phenol based solvents with $\mathrm{CP}$ through both the cyanide group and the pyridine nitrogen in the aromatic ring. Additionally, phenols can form self-associates, and also the oligomers of phenols can complex with CP as depicted in Fig. 3. The model [23] could describe the experimental data with high accuracy, but needed a large amount of data to regress the parameters. To simplify the system in order to minimize computational efforts and the required data-points, a simplified model was developed. The model is based on the insights from the previous study. Instead of modeling all complexations between the phenolic extractant and its oligomers with $\mathrm{CP}$ individually, all interactions were lumped in a single equilibrium reaction (Eq. (1)). Eq. (1) describes the complexation reaction between $\mathrm{CP}$ and DBP with the formation of $\left((\mathrm{CP})_{n} \mathrm{DBP}\right)$ complexes with average stoichiometry designated by $n$. From the previous analysis it can be concluded that multiple phenol molecules can complex with $\mathrm{CP}$, and therefore $n$ indicates the overall stoichiometry and equals $i+j$ as in Fig. 3 .

$n \mathrm{CP}+\mathrm{DBP} \leftrightarrows(\mathrm{CP})_{n} \mathrm{DBP}$

The complexation constant $K_{\mathrm{c}}^{\mathrm{app}}\left[\left(\mathrm{m}^{3} \mathrm{~mole}^{-1}\right)^{1-n}\right]$ describes the thermodynamic equilibrium and is defined by Eq. (2) where all the concentrations are expressed in $\left[\mathrm{mole}^{-3}\right]$. Since the pyridine nitrogen and cyanide nitrogen do not have the same reactivity, and self-association of DBP is not separately included, the complexation constant is defined as an apparent complexation constant in which all these effects are lumped. Furthermore, the physical solubility of $\mathrm{CP}$ in the organic phase was neglected and the stoichiometry was assumed to be independent of the concentration of $\mathrm{CP}$ in the organic phase. In Eq. (2) all concentration are expressed as molar concentration [mole $\mathrm{m}^{-3}$ ] and the overbar designates the concentration in the organic phase.

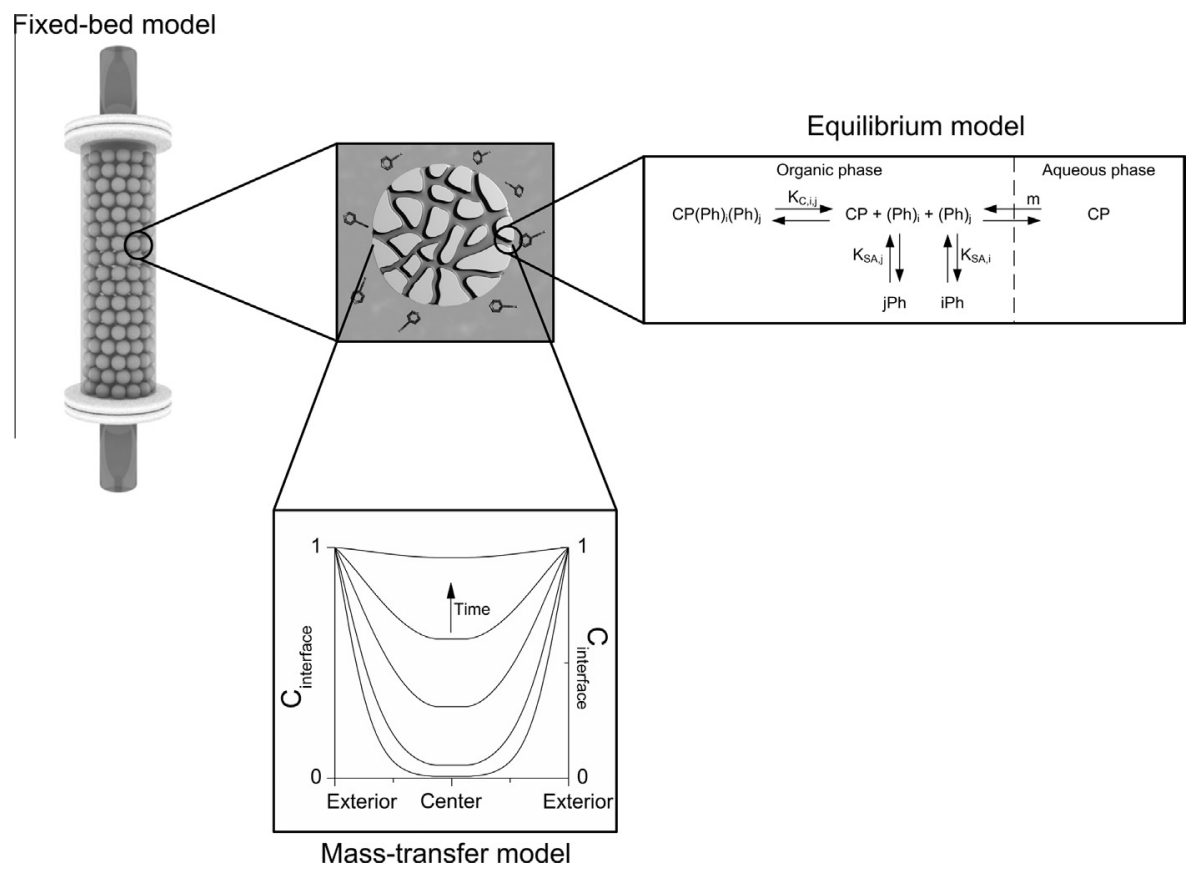

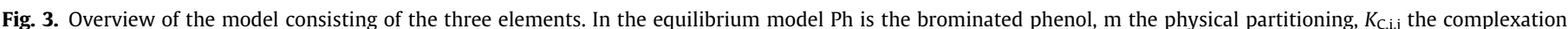

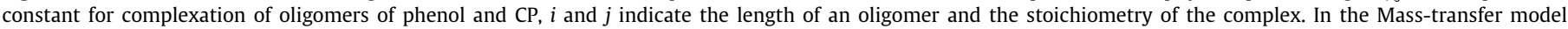
hypothetical concentration gradients in the SIR are displayed to illustrate how the concentration gradients build up in time inside the pores of the SIR particle. 
$K_{\mathrm{c}}^{\mathrm{app}}=\frac{\left[\overline{(\mathrm{CP})_{n} \mathrm{DBP}}\right]}{[\overline{\mathrm{CP}}]^{n} \cdot[\mathrm{DBP}]}$

The thermodynamic equilibrium model is applied in the expression for the isotherm, given in Eq. (3). The isotherm is defined in a similar way as reported for the extraction of citric acid by tri-n-octylamine [17]. It can be considered as a modified Langmuir isotherm, with as main difference the stoichiometry of the complexation reaction that is included by the power $n$.

$q_{\mathrm{eq}}=\left(\frac{K_{\mathrm{c}}^{\mathrm{app}} \cdot[\overline{\mathrm{DBP}}]_{\mathrm{ini}} \cdot[\mathrm{CP}]^{n}}{1+K_{\mathrm{c}}^{\mathrm{app}} \cdot[\mathrm{CP}]^{n}}\right) \cdot q_{\mathrm{S}} \cdot M_{\mathrm{w}, \mathrm{CP}}$

In Eq. (3), $[\overline{\mathrm{DPB}}]_{\mathrm{ini}}$ is the initial phenol concentration [mole $\left.\mathrm{m}^{-3}\right]$, [CP] is the equilibrium aqueous phase concentration of $\mathrm{CP}$ [mole $\mathrm{CP} \mathrm{\textrm {m } ^ { - 3 }}$ solvent], $q_{\mathrm{S}}$ is the solvent loading of the SIR particle [ $\mathrm{m}^{3}$ solvent $\left.\mathrm{kg}^{-1} \mathrm{SIR}\right], M_{\mathrm{w}, \mathrm{CP}}$ is the molecular weight of $\mathrm{CP}$ [g mole $\mathrm{g}^{-1}$ ] and $\mathrm{q}_{\mathrm{eq}}$ is the loading of the SIR [ $\left.\mathrm{g} \mathrm{CP} \mathrm{kg}^{-1} \mathrm{SIR}\right]$. The parameters $K_{\mathrm{c}}^{\mathrm{app}}$ and $n$ were regressed to the experimental data. Next to the capacity, the selectivity of the solvent is of great importance as the aim is to selectively recover $\mathrm{CP}$ from a mixture also containing SN and HAc. The selectivity was evaluated on the basis of the capacity factors. The capacity factor ( $\mathrm{CF}\left[\mathrm{m}^{3} \mathrm{~kg}^{-1}\right]$ ) was defined as the ratio between the equilibrium concentration in the aqueous phase and the amount adsorbed by the SIR at that concentration as defined in Eq. (4).

$C F=\frac{q_{\mathrm{eq}}}{C_{\mathrm{eq}, \mathrm{aq}}}$

The selectivity $(S[-])$ of the solvent for $\mathrm{CP}$ over HAc is then defined by Eq. (5), and the selectivity of the solvent for $\mathrm{CP}$ over SN by Eq. (6).

$S_{\mathrm{CP}, \mathrm{HAC}}=\frac{C F_{\mathrm{CP}}}{C F_{\mathrm{HAC}}}$

$S_{\mathrm{CP}, \mathrm{SN}}=\frac{C F_{\mathrm{CP}}}{C F_{\mathrm{SN}}}$

\subsection{Mass-transfer}

The overall rate of mass-transfer in SIRs is typically a function of the diffusivity of the solute in the organic phase, and by calculation of the mass-transfer rates the length of the mass-transfer zone in a fixed bed column can be estimated. Several models in the literature have been developed based on empirical correlations like the shrinking core model $[15,16]$, Elvoich equation [24] and models that describe the combined diffusion and chemical reaction inside the SIR $[11,15,25]$. In this study we evaluated both the linear driving force model (LDF-model) [26] and a model based on Fickian diffusion [27], in order to evaluate their applicability to describe both loading and regeneration experiments.

In the model based on Fickian diffusion, the mass-transfer rate depends on the diffusivity of the solute in the organic phase and can be described by Fick's second law of diffusion as defined by Eq. (7). Here, in contrast to the Maxwell-Stefan approach for multi-component diffusion [28], it is assumed that the mass-transfer rate can be fully described by a single diffusion coefficient of $\mathrm{CP}$ through the solvent. In Eq. (7), $c_{\overline{\mathrm{CP}}}$ is the concentration of $\mathrm{CP}$ in the solvent [mole $\mathrm{CP} \mathrm{m}^{-3}$ solvent], $r$ is the radial position in the SIR particle [m], $t$ is the time [s] and D is the effective diffusivity $\left[\mathrm{m}^{2} \mathrm{~s}^{-1}\right]$. The effective diffusion coefficient is defined as the diffusion coefficient of $\mathrm{CP}$ through the solvent corrected for the pore size and orientation of the resin and is obtained by regressing Eq. (7) to the data obtained with zero-length column experiments. $\left.\frac{\partial c_{\overline{\mathrm{CP}}}}{\partial t}\right|_{\mathrm{r}}=-D \cdot \frac{\partial^{2} c_{\overline{\mathrm{CP}}}}{\partial r^{2}}$

The SIR is assumed to be spherically symmetrical, and therefore the concentration gradients in the center of the SIR are equal to zero as boundary condition (Eq. (8), see also Fig. 3). In a previous study it was shown that due to the high viscosity of the solvent, the mass-transfer limitations will be completely in the organic phase inside the pores of the SIR [21]. For this reason mass-transfer resistance in the aqueous film was neglected and the organic side interface concentration was equal to the equilibrium concentration as defined by Eq. (9).

$\left.\frac{\partial c_{\overline{\mathrm{CP}}}}{\partial t}\right|_{r=0}=0$

$\left.q\right|_{r=R}=\left(\frac{K_{\mathrm{c}}^{\mathrm{app}} \cdot[\overline{\mathrm{DBP}}]_{\mathrm{ini}} \cdot[\mathrm{CP}]^{n}}{1+K_{\mathrm{c}}^{\mathrm{app}} \cdot[\mathrm{CP}]^{n}}\right) \cdot M_{\mathrm{w}, \mathrm{CP}}$

The concentration of the aqueous phase can be described by Eq. (10), employing Fick's first law of diffusion. Where $3 / R$ is the effective surface area $\left[\mathrm{m}^{2} \mathrm{~m}^{-3}\right], V_{\mathrm{SIR}}$ the volume of the solvent impregnated resin $\left[\mathrm{m}^{3}\right]$ and $V_{\mathrm{aq}}$ the volume of the aqueous phase used in an experiment $\left[\mathrm{m}^{3}\right]$.

$\frac{\partial c_{\mathrm{CP}}}{\partial t}=-\left.\frac{3}{R} \cdot D \cdot \frac{\partial c_{\overline{\mathrm{CP}}}}{\partial r}\right|_{r=R} \cdot \frac{V_{\mathrm{SIR}}}{V_{\mathrm{aq}}}$

Where the Fick-diffusion model gives the more complete description of the mass-transfer, it might be possible to reduce computational efforts by applying a simpler mass-transfer model like the LDF-model defined by Eq. (11) [26].

$\frac{\partial q}{\partial t}=K_{\mathrm{LDF}} \cdot\left(q_{\mathrm{eq}}^{\mathrm{t}}-q^{\mathrm{t}}\right)$

Eq. (11) relates an overall mass-transfer rate to the difference between the equilibrium capacity at time $t\left(q_{\mathrm{eq}}^{\mathrm{t}}\left[\mathrm{g} \mathrm{CP} \mathrm{kg}{ }^{-1} \mathrm{SIR}\right]\right)$, the actual capacity at time $t\left(q^{t}\left[\mathrm{~g} \mathrm{CP} \mathrm{kg}^{-1} \mathrm{SIR}\right]\right)$ and the overall mass-transfer coefficient $\left(K_{\mathrm{LDF}}\left[\mathrm{s}^{-1}\right]\right)$. The $K_{\mathrm{LDF}}$ depends on the diffusivity of $\mathrm{CP}$ through the organic phase and can be estimated by regressing Eq. (11) to the experimental data obtained with zerolength column experiments.

\subsection{Fixed bed column model}

In order to describe the concentration profile in a fixed bed, the previously derived equations for the equilibrium and the masstransfer rate were coupled to the overall mass-balance defined by Eq. (12). The left-hand side of Eq. (12) contains the none-stationary terms that describe the time-dependent change in the concentration in the aqueous phase and the mass-transfer rate to the SIR particles, that was either calculated with the Fick model or the LDF-model. The right-hand side contains the convective and dispersive term.

$\varepsilon_{\mathrm{b}} \cdot \frac{\partial c_{\mathrm{CP}}}{\partial t}+\left(1-\varepsilon_{\mathrm{b}}\right) \cdot \rho_{\mathrm{SIR}} \cdot \frac{\partial q}{\partial t}=-\frac{Q_{\mathrm{v}}}{A \cdot L} \frac{\partial c_{\mathrm{CP}}}{\partial z}+\varepsilon_{\mathrm{b}} \cdot \frac{D_{\mathrm{ax}}}{L^{2}} \cdot \frac{\partial^{2} c_{\mathrm{CP}}}{\partial z^{2}}$

In Eq. (12) $C_{\mathrm{CP}}\left[\mathrm{g} \mathrm{CP} \mathrm{L}^{-1}\right.$ ] is the concentration $\mathrm{CP}$ in the aqueous phase, $\varepsilon_{\mathrm{b}}$ [-] is the void fraction of the bed, $q$ [g CP kg$\left.{ }^{-1} \mathrm{SIR}\right]$ the loading of the SIR, $Q_{\mathrm{v}}\left[\mathrm{m}^{3} \mathrm{~s}^{-1}\right]$ the volumetric flow rate, $A\left[\mathrm{~m}^{2}\right]$ the cross-sectional area of the column, $L[\mathrm{~m}]$ the length of the column, $D_{\mathrm{ax}}\left[\mathrm{m}^{2} \mathrm{~s}^{-1}\right]$ the axial dispersion coefficient and $z[-]$ is the normalized axial coordinate defined as the position in the column divided by the length of the column.

In the regeneration cycle, the $\mathrm{pH}$ of the aqueous phase is reduced strongly, this leads to protonation of aqueous $\mathrm{CP}$, resulting in a shift in the equilibrium distribution. As only the neutral form 
of $\mathrm{CP}$ is soluble in the organic phase [29], the pH swing results in a reduction of the equilibrium capacity, and the SIR particles are regenerated. The equilibrium of the protonation reaction can be described by Eq. (13). Because of the instantaneous protonation, the aqueous phase composition using Eq. (13) is solved simultaneously with Eq. (12) to describe the concentration profiles of the neutral form and the protonated form of $\mathrm{CP}$ and at each position in the fixed bed.

$K_{\mathrm{a}}=\frac{[\mathrm{CP}] \cdot\left[\mathrm{H}^{+}\right]}{\left[\mathrm{CPH}^{+}\right]}$

The $\mathrm{pH}$ in the bed is a function of the $\mathrm{pH}$ in the feed. At the end of the loading cycle, the $\mathrm{pH}$ is uniform throughout the bed, and when starting to percolate the column with the hydrochloric acid solution the concentration profile is described by the axial dispersion term, as depicted in Eq. (14).

$\varepsilon_{\mathrm{b}} \cdot \frac{\partial c_{\mathrm{H}^{+}}}{\partial t}=-\frac{Q_{\mathrm{v}}}{A \cdot L} \frac{\partial c_{\mathrm{H}^{+}}}{\partial z}+\varepsilon_{\mathrm{b}} \frac{D_{\mathrm{ax}}}{L^{2}} \cdot \frac{\partial^{2} c_{\mathrm{H}^{+}}}{\partial z^{2}}$

The boundary conditions of Eqs. (12) and (14) were as follows, the concentration at $z=0$ is equal to the feed concentration (Eq. (15)) and a smooth outlet concentration profile was assumed (Eq. (16)). In Eqs. (15) and (16), $L[\mathrm{~m}]$ is the length of the fixed bed.

$\left.c_{\mathrm{H}^{+}, \mathrm{CP}}\right|_{z=0}=c_{\mathrm{H}^{+}, \mathrm{CP}, \text { Feed }}$

$\left.\frac{\partial c_{\mathrm{H}^{+}, \mathrm{CP}}}{\partial z}\right|_{z=L}=0$

The axial dispersion coefficient was calculated using the Chung-Wen correlation. In a previous study it was shown that the axial dispersion in the case of a SIR consisting of Amberlite XAD4 impregnated with 4-nonylphenol had hardly any effect on the breakthrough profile [21]. However, it was required to estimate the concentration gradient of the acid through the column and was therefore included in the model. The Chung and Wen correlation [30] is given in Eq. (17), where $u$ is the interstitial velocity $\left[\mathrm{m} \mathrm{s}^{-1}\right]$, Re is the Reynolds number and $d_{\mathrm{p}}$ is the particle diameter $[\mathrm{m}]$. The concentration gradients of SN and HAc were both calculated according to Eq. (14) as they were assumed to have a negligible concentration in the organic phase, an assumption that was validated experimentally (vide infra).

$D_{\mathrm{ax}}=\frac{\varepsilon_{\mathrm{b}}}{0.2+0.0011 \cdot R e^{0.48}} \cdot u \cdot d_{\mathrm{p}}$

\section{Experimental}

\subsection{Chemicals}

Amberlite XAD4, 4-cyanopyridine (>99.9\%), hexane (>97\%), ethanol $(>99.5 \%)$, acetic acid $(>99.7 \%)$, succinonitrile $(>99 \%)$, pyridine $(>99.9 \%)$ were supplied by Sigma-Aldrich, the Netherlands.

\subsection{Custom synthesized solvent}

\subsubsection{General information}

Starting materials for the synthesis of 3,5-dibromo-4-(4,6,6trimethylheptyl)phenol and 3,5-dibromo-4-(4,8-dimethylnonyl)phenol were commercially available and were used without further purification. ${ }^{1} \mathrm{H}$ NMR spectra were recorded at $300 \mathrm{MHz}$ on either a VNMRS spectrometer or a MP300 spectrometer (both from Oxford Instruments), ${ }^{13} \mathrm{C}$ NMR spectra were recorded on the MP300 spectrometer (at $75 \mathrm{MHz}$ ), and multiplicities were distinguished using an attached proton test (APT). HPLC-MS apparatus: Agilent 1100 series with UV detector and HP 1100 MSD mass detector. GC-MS apparatus: Agilent 6890 series with Agilent 5973 mass selective detector; Column: Varian FactorFour VF-5MS (CP9013), $\quad 30 \mathrm{~m} \times 250 \mu \mathrm{m} \times 0.25 \mu \mathrm{m}$. Temperature program: $60{ }^{\circ} \mathrm{C}$ initially, and after 2 min a $20^{\circ} \mathrm{C} /$ min ramp until $250{ }^{\circ} \mathrm{C}$. Inj. temp: $250^{\circ} \mathrm{C}$; Inj vol.: $3 \mu \mathrm{L}$; Split ratio: $75: 1$; Detector: MSD EI.

\subsubsection{Synthesis procedure of the brominated phenol}

The developed route for the synthesis of compounds $\mathbf{1}$ and $\mathbf{2}$ is depicted in Fig. 4, and starts from 3,5-dibromophenol $\mathbf{3}$ which was protected by a bulky trimethylsilyl group. The para-position of compound 4 was selectively deprotonated by lithium diisopropylamine (LDA) as reported previously [33], and the anion quenched with dimethylformamide (DMF) to afford aldehyde 5. After initial unsuccessful attempts to keep the TMS protected group intact by quenching the reaction with base, pure 2,6-dibromo-4-hydroxybenzaldehyde $\mathbf{5}$ was isolated after quenching with acid. Subsequently, compound $\mathbf{5}$ was treated with dimethyl sulfate (DMS) in acetone to afford 6 in 95-99\% yield (in water the reaction did not proceed well, even after adding additional portions DMS).

Grignard reactions on $\mathbf{6}$ were attempted with alkylmagnesium iodides prepared from alkyl iodides $\mathbf{9}$ and $\mathbf{1 0}$, and with alkylmagnesium bromides prepared from alkyl bromides $\mathbf{1 1}$ and $\mathbf{1 2}$ (Fig. 5). Product $\mathbf{7}$ was formed from $\mathbf{9}$ and $\mathbf{1 0}$ in low yield (20$30 \%$ ) probably due to the formation of by-products via cross-coupling reactions, starting from 11 and 12, the yield improved to 57\%.

Substantial amounts of benzylic alcohol 13, and monobromides 14 and 15 were formed during the 1,2-addition reaction (Fig. 6). Bromides $\mathbf{1 1}$ and $\mathbf{1 2}$ were prepared in excellent yield from their commercially available alcohols by treatment with $\mathrm{HBr}$ and sulfuric acid [34,35]. Dehydroxylation of compounds 7 was accomplished by reaction with triethylsilane and borontrifluoride etherate in quantitative yield. Demethylation with $\mathrm{BBr}_{3}$ gave target compounds 1 and $\mathbf{2}$ in respectively 89\% and 78\% yield after column chromatography. For additional information regarding the synthesis of the intermediates see the supplementary information.

\subsection{SIR preparation}

Amberlite XAD4 was washed first with water and then with ethanol prior to the impregnation, after washing with ethanol the resin was dried during $24 \mathrm{~h}$ at $80^{\circ} \mathrm{C}$. The dry resin was brought into contact with the DBP diluted in hexane during $24 \mathrm{~h}$ and atmospheric pressure in an incubator at a stirring rate of $100 \mathrm{rpm}$. After this time the hexane was removed in a rotary evaporator at $25^{\circ} \mathrm{C}$ and 250 mbar until all hexane was removed. DBP remains inside the pores of the resin and the loading of the SIR was determined by measuring the increase in the weight. The resin was characterized by measuring the density using an Accupyc 1330 pycnometer (Micrometrics). The loading of the SIRs was $0.42 \mathrm{~mL} / \mathrm{g}$ SIR, corresponding with $95 \%$ of the maximum porosity to allow the organic phase to expand without solvent losses and the density of the impregnated SIR was $1.24 \mathrm{~g} / \mathrm{mL}$.

\subsection{Batch-wise contacting experiments}

Equilibrium adsorption measurements were performed by contacting 0.3 gram of the SIR during 3 days in an incubator with a stirring rate of $300 \mathrm{rpm}$ with aqueous $\mathrm{CP}$-solutions varying in initial concentration between 0.1 and $10 \mathrm{~g} / \mathrm{L}$. The liquid-liquid extraction experiments were conducted by mixing the bulk liquid organic phase with aqueous CP-solutions of concentration 0.5$3.5 \mathrm{~g} / \mathrm{L}$, in solvent-to-feed ratios from 0.1 to 1 . The two liquid phases were magnetically stirred during $24 \mathrm{~h}$. After the samples were equilibrated, the aqueous phase was analyzed using gas chromatography, the SIR loading and organic phase composition were determined on the basis of a mass balance. 

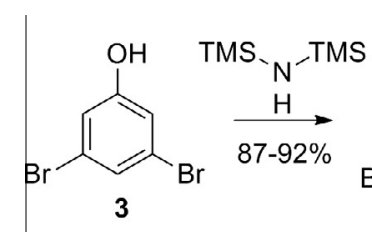<smiles>CS(=O)(=O)Oc1cc(Br)c(Br)c(Br)c1</smiles><smiles>O=Cc1c(Br)cc(O)cc1Br</smiles><smiles>COc1cc(Br)c(C=O)c(Br)c1</smiles><smiles>CC(C)CCC(C)CC(C)CCC(C)CC(C)C</smiles><smiles>[R]C(O)c1c(Br)cc(OC)cc1Br</smiles><smiles>CCOC(=O)OCC</smiles>

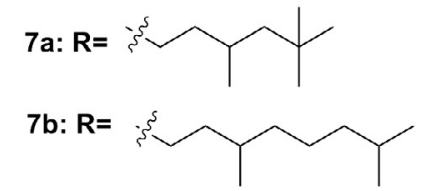<smiles>CC(C=[Ru])CC(C)CCC(C)(C)C</smiles>

8b: $\mathbf{R}=$<smiles>[R]Cc1c(Br)cc(OC)cc1Br</smiles><smiles>[R]Cc1c(Br)cc(O)cc1Br</smiles>

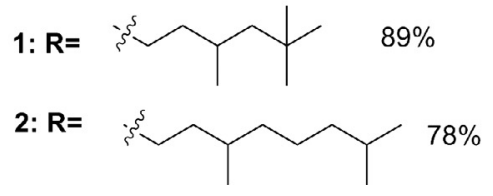

Fig. 4. Route toward target compounds $\mathbf{1}$ and $\mathbf{2}$.<smiles>CC(C)CCCC(C)CCCl</smiles>

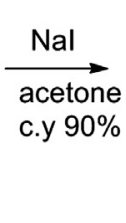<smiles>CC(CCI)CC(C)(C)C</smiles><smiles>CC(C)CCCC(C)CCI</smiles><smiles>CC(CCO)CC(C)(C)C</smiles>

$\mathrm{HBr}, \mathrm{H}_{2} \mathrm{SO}_{4}$

$80-92 \%$<smiles>CC(C)CCCC(C)CCO</smiles><smiles>CC(CCBr)CC(C)(C)C</smiles><smiles>CC(C)CCCC(C)CCBr</smiles>

Fig. 5. Preparation of alkylhalides.<smiles>COc1cc(Br)c(CO)c(Br)c1</smiles><smiles>COc1ccc(C(C)O)c(Br)c1</smiles><smiles>COc1ccc(C(O)[18OH])c(Br)c1</smiles>

Fig. 6. By-products formed in the Grignard reaction.

\subsection{Zero-length column experiments}

The rate of the uptake of CP by the SIR was determined in a zero-length column setup (ZL-column) [31,32]. In this setup a thin layer of SIR particles $(2 \mathrm{~mm})$ is placed inside a glass column (Ominfit, England) and a solution containing 0.5 or $3 \mathrm{~g} / \mathrm{L}$ of $\mathrm{CP}$ was circulated through the column while measuring the concentration with a Smartline 2500 inline UV-detector (Knauer GmbH, Germany). In the experiments the aqueous phase volume used was chosen such that the aqueous phase concentration reduced with 30\% during the experiment. After equilibrium was attained, the column was rinsed with demineralized water to remove the $\mathrm{CP}$, and was fed in recycle mode with a pH 1 hydrochloric acid solution, while measuring the concentration with the inline UV-detector. The flow rate with which the solutions were pumped through the bed was $25 \mathrm{~mL} /$ min at which level it was ensured that the mass-transfer resistance in the aqueous phase could be neglected and the mass-transfer rate is only dependent on the diffusion through the organic phase inside the SIR particle.

\subsection{Fixed bed column experiments}

The breakthrough profiles were measured in fixed bed column experiments. In these experiments a glass column (Omnifit, England) was stacked with a bed of SIR particles with a bed height of $28 \mathrm{~cm}$ and a bed diameter of $1.5 \mathrm{~cm}$. The loading and regeneration cycles were performed at flow rates of $1,2.5$ and $5 \mathrm{~mL} / \mathrm{min}$ pumped with a Knauer HPLC pump (Knauer GmbH, Germany). The feed solution consisted of $500 \mathrm{ppm} \mathrm{CP}$, or a mixture of $500 \mathrm{ppm} \mathrm{CP}, 500 \mathrm{ppm}$ SN and $4.5 \mathrm{~g} / \mathrm{L}$ HAc. The effluent was analyzed with a Smartline 2500 inline UV-detector (Knauer $\mathrm{GmbH}$, Germany) to determine the concentration of $\mathrm{CP}$. The concentration of SN and HAc were measured by gas chromatography. The 
regeneration procedure was started when the bed was fully saturated and contained the solution used in the loading cycle. The feed consisted of a $\mathrm{pH} 1$ hydrochloric acid solution. The effluent was analyzed using gas chromatography during the regeneration cycle.

\subsection{Gas chromatography}

Gas chromatography was used for the analysis of the equilibrium measurements, the effluent of the fixed-bed column experiments during regeneration and the measurement of HAc and SN in the fixed-bed column experiments. For the equilibrium measurements and the measurement of the concentration of HAc and SN during the loading cycle with the fixed-bed column experiments, a sample of the aqueous phase was taken and filtered over a 45 micrometer filter. In the regeneration of the resins in fixedbed column experiments the sample was first mixed with a $\mathrm{pH}$ 14 sodium hydroxide solution to set the $\mathrm{pH}$ to 7 . A sample of $1.2 \mathrm{~mL}$ was taken and mixed with $0.3 \mathrm{~mL}$ of a $0.10 \mathrm{~g} / \mathrm{L}$ pyridine solution which was used as internal standard. The sample was then injected in a Varian CP-3800 gas chromatograph (Varian Inc, the Netherlands) equipped with a $25 \mathrm{~m} \times 0.53 \mathrm{~mm}$ CP-WAX column and flame ionization detector. The injected sample volume was $1 \mu \mathrm{L}$, the initial column temperature was $50^{\circ} \mathrm{C}$, followed by a ramp of $20^{\circ} \mathrm{C} / \mathrm{min}$ to $200^{\circ} \mathrm{C}$, after this ramp the temperature was directly increased to $240{ }^{\circ} \mathrm{C}$ with a ramp of $50{ }^{\circ} \mathrm{C} / \mathrm{min}$. Each sample was injected 3 times; the average relative standard deviation for the measurement of all compounds were below $0.5 \%$.

\subsection{Mathematical modeling}

The thermodynamic equilibrium model was programmed in Matlab, and data regression was done with the global search function. The mathematical model to calculate the breakthrough curves was programmed in gProms model builder 3.3.1, and the equations were solved using the centered finite discretization method. Regression of the diffusion coefficient was also done with gProms model builder 3.3.1 using the data regression tool with a constant relative variance model set at a relative variance of $3 \%$.

\section{Results and discussion}

\subsection{Model development}

\subsubsection{Equilibrium model}

Batch-wise equilibrium experiments were performed to study the thermodynamic equilibrium of the extraction of $4 \mathrm{CP}$ by the phenolic solvent. Both liquid-liquid extraction experiments to study the capacity of the solvent and equilibrium adsorption measurements to determine the capacity of the SIR were performed. In Fig. 7a the distribution coefficient measured in the liquid-liquid extraction experiments and in the SIR adsorption experiments are presented and in Fig. 7b the SIR adsorption isotherm is presented. In both figures the results of the model after dataregression is also included.

In Fig. 7a it can be observed that the distribution coefficient varies from a maximum value of 290 to a value of 35 over the concentration range from $0.02 \mathrm{~g} / \mathrm{L}$ to $6 \mathrm{~g} / \mathrm{L}$ 4-cyanpyridine in the aqueous phase. It can also be observed that the distribution coefficients obtained by the liquid-liquid extraction experiments follow the same trend as those measured by SIR experiments, which results in the conclusion that the SIR capacity is fully determined by the capacity of the solvent. In Fig. 7b, it can be observed that the capacity of the SIR follows a favorable isotherm as expected. It is clearly visible that the standard Langmuir isotherm, assuming a stoichiometry of $1: 1(\mathrm{CP}: \mathrm{DBP})$, was not able to describe the data accurately,
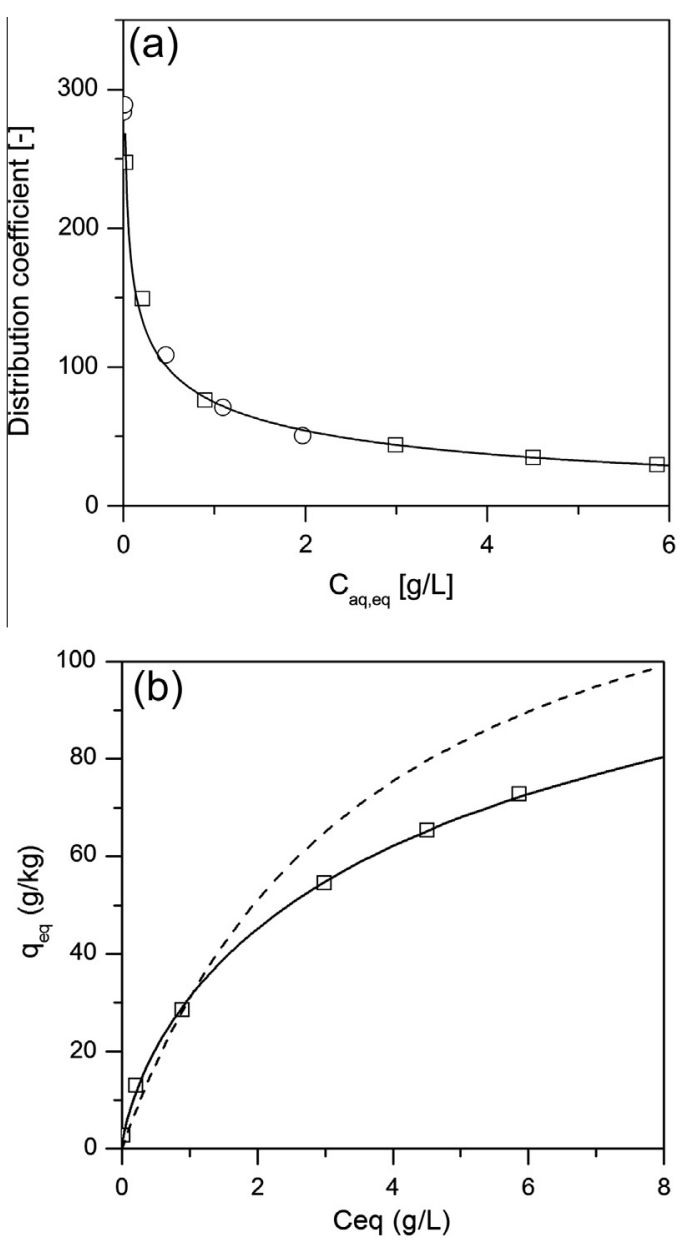

Fig. 7. (a) Distribution coefficient measured by liquid-liquid extraction experiments $(O)$ and SIR experiments $(\square)$ and modeled with the isotherm (continuous line). (b) The SIR isotherm regressed with the modified Langmuir isotherm (continuous line) and the standard Langmuir isotherm (dashed line), the symbols are the experimental data points.

while the modified Langmuir isotherm with a stoichiometry of $n: 1 \quad(C P: D B P)=0.73: 1$ and a complexation constant of 0.052 $\left(\mathrm{m}^{3} \mathrm{~mole}^{-1}\right)^{1-n}$ gave a very good fit of the model with a mean relative error of $2.3 \%$. The capacity reaches up to $70 \mathrm{~g} / \mathrm{kg}$ at an aqueous phase concentration of $6 \mathrm{~g} / \mathrm{L}$ of CP. The value of $n$ is smaller than 1 , indicating that multiple DBP molecules can attach to $1 \mathrm{CP}$ molecule. This is in accordance with the expectations, because both the pyridine and the nitrile functionalities are Lewis bases that may complex with the Lewis acid phenol. Another parameter of interest was the selectivity, defined as the ratio of the capacity factors of $\mathrm{CP}$ in comparison with $\mathrm{SN}$ and $\mathrm{HAc}$. In the adsorption experiment with a feed consisting of $500 \mathrm{ppm} \mathrm{CP}, 500 \mathrm{ppm} \mathrm{SN}$ and $4.5 \mathrm{~g} / \mathrm{L}$ HAc no significant reduction in the concentration of SN and HAc was measured while the concentration of $\mathrm{CP}$ was reduced by $60 \%$. These results indicate that the selectivity of this SIR is above 500 for CP with both succionitrile and HAc, given the analytical uncertainty in the measurement of these compounds.

\subsubsection{Mass-transfer}

ZL-column experiments were conducted to study the masstransfer in the SIR. The Fick-diffusion model and the LDF-model were regressed to the experimental data obtained with an initial concentration of 0.5 and $3 \mathrm{~g} / \mathrm{L}$, resembling the operating conditions in the fixed bed column in loading and regeneration. After equilibrium was reached, the regeneration was performed with an $\mathrm{HCl}$ 
solution of $\mathrm{pH}=1$. The results are presented in Fig. 8, where $c / c_{0}$ for a loading experiment was defined as the ratio of the measured concentration over the initial concentration, and for the regeneration cycle it was defined as the ratio of the measured concentration over the equilibrium concentration obtained at the end of the regeneration cycle.
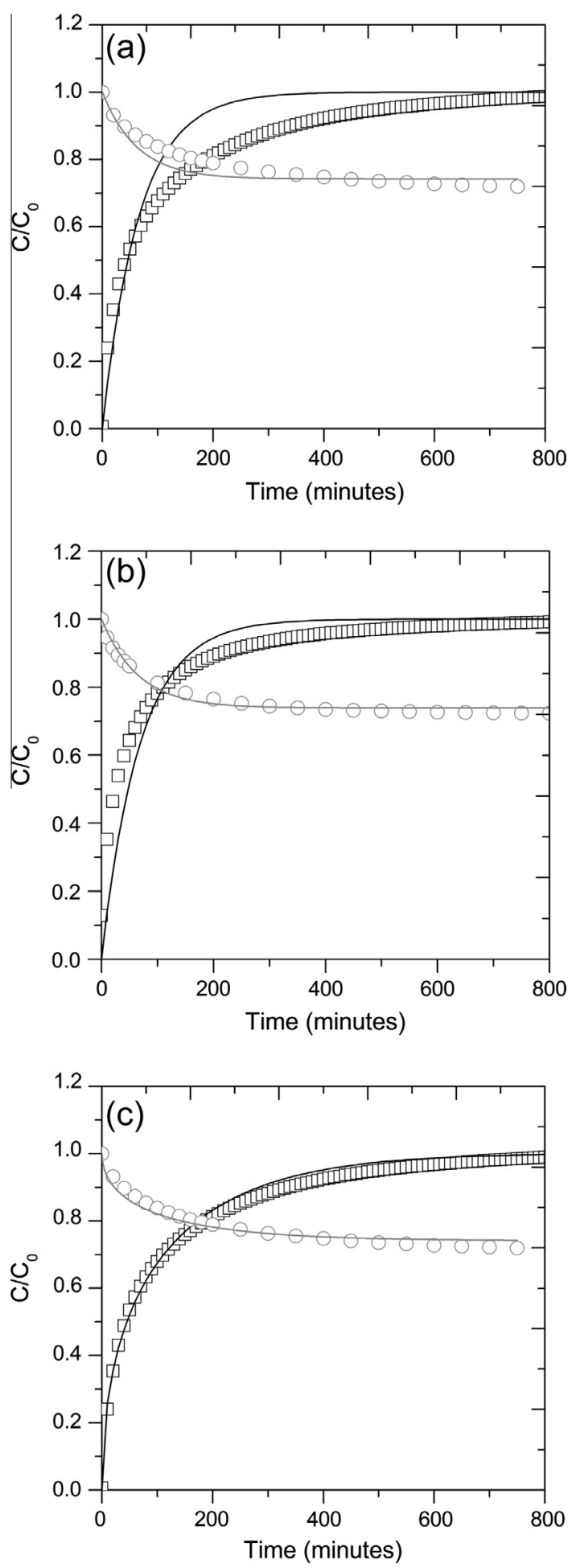

Fig. 8. Results of the zero-length column experiments with the LDF-model for an initial concentration of $0.5 \mathrm{~g} / \mathrm{L}(\mathrm{A}), 3 \mathrm{~g} / \mathrm{L}$ (B) and with the Fick-model for an initial concentration of $0.5 \mathrm{~g} / \mathrm{L}(\mathrm{C})$ and $3 \mathrm{~g} / \mathrm{L}(\mathrm{D})$. Lines are the model results: regeneration cycle (black) and the loading cycle (grey). Symbols are the experimental data for the loading cycle $(\bigcirc)$ and the regeneration cycle $(\square)$.
In Fig. 8a and b it can be observed that the LDF-model is not able to describe all data accurately. Especially the regeneration cycle at an initial aqueous phase concentration of $0.5 \mathrm{~g} / \mathrm{L}$ is largely overestimated, and during the loading cycle at $0.5 \mathrm{~g} / \mathrm{L}$ a slight overestimation of the mass-transfer rate was made. At a higher concentration the differences tend to become smaller. The LDF-model assumes a mass-transfer coefficient that is independent on the concentration, the results however show that the mass-transfer rates are depending on the concentration and as a result the LDF-model could not describe all experimental data.

The Fick-model, for which the results are presented in Fig. 8c and $\mathrm{d}$, gives a better description. The loading cycles at both 0.5 and $3 \mathrm{~g} / \mathrm{L}$ were well described, and the regeneration cycle with $0.5 \mathrm{~g} / \mathrm{L}$ as initial concentration is perfectly described with Fickian diffusion. It can however be observed that at an initial concentration of $3 \mathrm{~g} / \mathrm{L}$ there is an underestimation of the mass-transfer rate during the regeneration cycle. The estimated value of the diffusion coefficient will be used in the next section to compare the model results in fixed-bed operation. The overall mass-transfer coefficient for the LDF model was estimated at $2.2 \cdot 10^{-4} \mathrm{~s}^{-1} \pm 2.2 \%$. The effective diffusion coefficient of CP in the SIR particle was estimated at $6.53 \cdot 10^{-13} \mathrm{~m}^{2} \mathrm{~s}^{-1} \pm 2.5 \%$. This low value of the diffusion coefficient can be explained by the high viscosity of the solvent, as also found for the transfer of $\mathrm{CP}$ in a SIR containing 4-nonylphenol as solvent [21].

\subsubsection{Loading cycle}

A fixed-bed column stacked with SIR particles was loaded with $\mathrm{CP}$ by displacing a feed with a $500 \mathrm{ppm}$ solution of $\mathrm{CP}$ through the column at varying flow rates. One additional experiment was performed with a mixture of $500 \mathrm{ppm} \mathrm{CP}, 500 \mathrm{ppm}$ SN and $4.5 \mathrm{~g} / \mathrm{L} \mathrm{HAc}$ at a flow rate of $5 \mathrm{~mL} / \mathrm{min}$. The breakthrough profiles estimated with the model and experimentally determined are presented in Fig. 9.

From Fig. 9 it can be observed that by reducing the flow rate, a narrowing of the breakthrough profiles occurs. This trend was also observed previously in the case of 4-nonylphenol impregnated in Amberlite XAD4 with CP as feed [21]. The narrowing of the breakthrough profile at lower flow rates can be explained by the reduced effect of the mass-transfer limitations due to the longer residence time of the percolated fluid in the column. Breakthrough of the column was defined as the moment when the outlet concentration was $1 \%$ of the feed concentration and occurred after approximately 5,10 and 23 bed volumes at a flow rate of $5,2.5$ and $1 \mathrm{~mL} / \mathrm{min}$, respectively. In Fig. 9a it can be observed that HAc and SN breakthrough immediately due to the very high selectivity of the SIR. The breakthrough profiles of HAc and SN were modeled, assuming the adsorption would be zero and the gradient was described by axial dispersion only. In Fig. 9a it may be observed that with this assumption the breakthrough profile of HAc and SN could be described well.

\subsubsection{Regeneration cycle}

After the column was fully saturated, it was regenerated with a $\mathrm{pH} 1 \mathrm{HCl}$ solution at a flow rate of $1,2.5$ and $5 \mathrm{~mL} / \mathrm{min}$. The outlet concentration of the column was monitored and the results were compared with the calculated values with the model using both the Fick and the LDF-model. In Fig. 10 the outlet concentration normalized to the original feed concentration as measured and calculated with both models are presented after percolating 1 bed volume through the bed, i.e. when the outlet concentration started increasing.

In Fig. 10, it can be observed that the outlet concentration is initially 7 times higher than the original feed concentration. At a $\mathrm{pH}$ of 1 , only $14 \%$ of CP is in its neutral form which results in a factor 7 reduction in the capacity and hence a factor 7 increase in the 

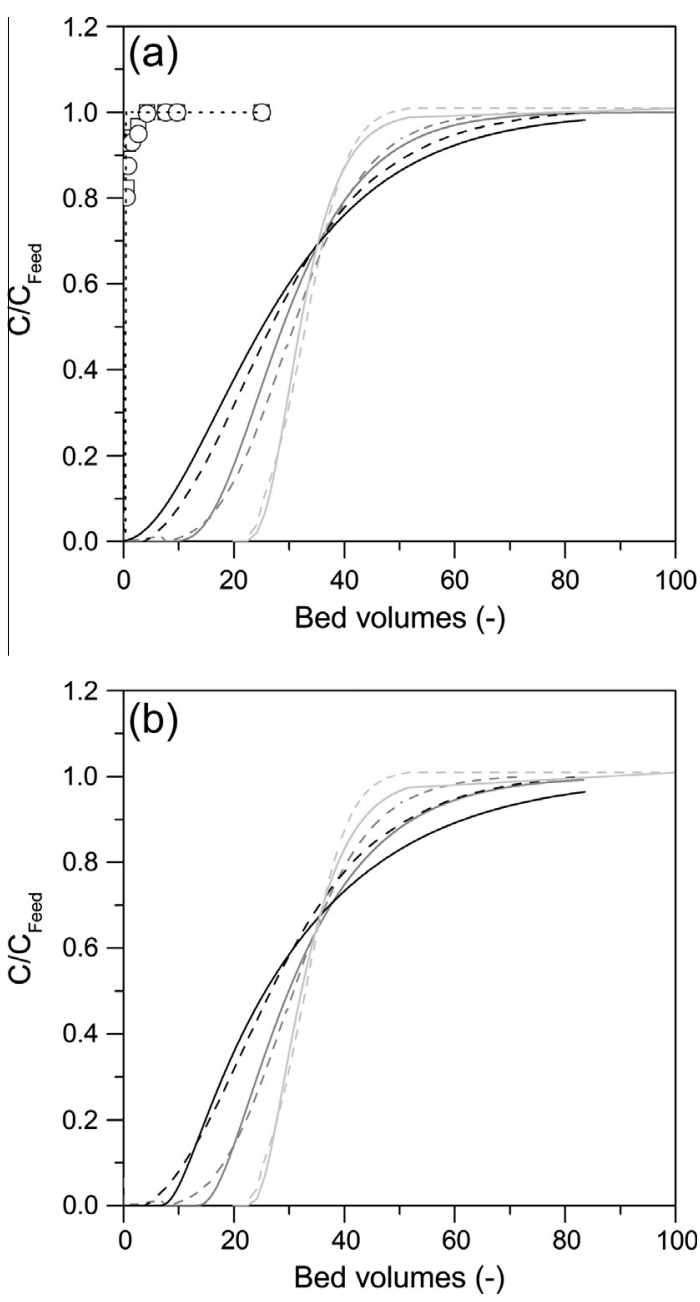

Fig. 9. Breakthrough profiles of SIR fixed-bed experiments: (a) LDF-model and (b) Fick model. Lines: flow rate $1 \mathrm{~mL} / \mathrm{min}$ (black), $2.5 \mathrm{~mL} / \mathrm{min}$ (dark grey) and $5 \mathrm{~mL} / \mathrm{min}$ (light grey), experimental results (dashed) and the model results (continuous). The black dotted line is the modeled breakthrough profile of SN and HAc. Symbols: HAc (○) and SN ( $\square$ ).

aqueous phase concentration at equilibrium. After this maximum was obtained, it gradually reduces with respect to time as the SIR particles are regenerated. In Fig. 10a the results of the LDFmodel are included, where it can be observed that at 5 and $2.5 \mathrm{~mL} / \mathrm{min}$ a large underestimation of this outlet concentration was obtained and only at $1 \mathrm{~mL} / \mathrm{min}$ the model agrees well with the experimental data. In Fig. $10 \mathrm{~b}$ it can be observed that the Fick-model agrees with the experimental data under all conditions. The main difference between the Fick-model and the LDF-model is that the LDF-model assumes a constant mass-transfer coefficient, while the mass-transfer rate in the Fick-model is inherently time-dependent.

\subsubsection{Model performance overview}

In the previous sub-sections the models were developed to describe the mass-transfer of $\mathrm{CP}$ from the aqueous phase to the organic phase inside the SIR with the LDF-model and Fick-model. A comparison of the accuracy of the two models was made, and the $R^{2}$-values that were obtained for the ZL-experiments and fixed bed experiments, for the loading and regeneration cycle are presented in Table 1.

In Table 1 it can be observed that the Fick-model is best applicable for the description of the mass-transfer rates as obtained in the ZL-column experiments as was previously concluded. The
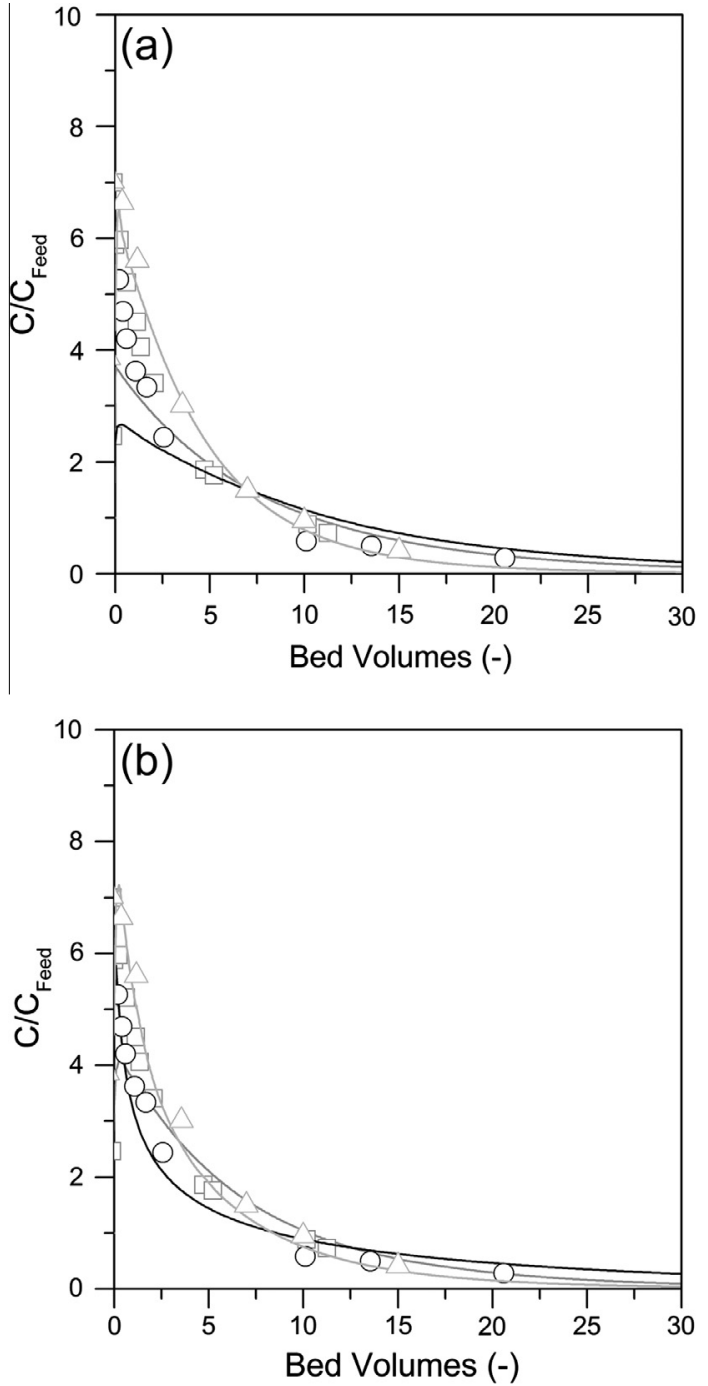

Fig. 10. Effluent concentration during regeneration, modeled with the LDF-model (a) and Fick model (b). Lines are model results: flow rate $5 \mathrm{~mL} / \mathrm{min}$ (black), $2.5 \mathrm{~mL} /$ min (dark grey) and $1 \mathrm{~mL} / \mathrm{min}$ (light grey). Symbols are experimental data: Flow rate $5 \mathrm{~mL} / \mathrm{min}(\bigcirc), 2.5 \mathrm{~mL} / \mathrm{min}(\square)$ and $1 \mathrm{~mL} / \mathrm{min}(\Delta)$.

Table 1

$R^{2}$-values obtained with the LDF and fick model for the ZL-experiments and fixed bed experiments in the loading and regeneration cycle.

\begin{tabular}{llll}
\hline & & Fick & LDF \\
\hline & & Fick & LDF \\
\hline Zero-length column experiment & & \\
Loading & $0.5 \mathrm{~g} / \mathrm{L}$ & 0.94 & 0.87 \\
& $3 \mathrm{~g} / \mathrm{L}$ & 0.97 & 0.98 \\
Regeneration & $0.5 \mathrm{~g} / \mathrm{L}$ & 0.99 & 0.69 \\
& $3 \mathrm{~g} / \mathrm{L}$ & 0.91 & 0.84 \\
Fixed bed experiments & & & \\
Loading & $1 \mathrm{~mL} / \mathrm{min}$ & 0.98 & 0.98 \\
& $2.5 \mathrm{~mL} / \mathrm{min}$ & 0.99 & 0.99 \\
& $5 \mathrm{~mL} / \mathrm{min}$ & 0.97 & 0.99 \\
Regeneration & $1 \mathrm{~mL} / \mathrm{min}$ & 0.99 & 0.98 \\
& $2.5 \mathrm{~mL} / \mathrm{min}$ & 0.96 & 0.78 \\
& $5 \mathrm{~mL} / \mathrm{min}$ & 0.95 & 0.45 \\
\hline
\end{tabular}

dependency of the mass-transfer on the concentration could not be described by the LDF-model. For the fixed-bed column experiments it can be concluded that during the loading cycle, both the 
Fick-model and LDF-model could describe all data accurately, and at a flow rate of $5 \mathrm{~mL} / \mathrm{min}$ the LDF-model was even more accurate than the Fick-model. At a fixed position in the bed the concentration changes from initially 0 to the feed concentration in time. This gradual increase in the concentration resulted in a small dependency of the mass-transfer coefficient with time, and therefore the LDF-model was able to describe the experimental data with sufficient accuracy. With the Fick-model however, the initial mass-transfer rate will be higher due to the steeper concentration gradients, this effect seems to be overestimated, resulting in a narrower breakthrough profile than experimentally obtained, and a higher accuracy with the LDF-model. For describing the regeneration of the column the Fick-model is best applicable, as the $R^{2}$-values are much higher than the LDF-model. It can clearly be observed that the LDF-model could not describe the data as function of flow rate and is only accurate at low flow rates where the residence time in the column is longer. The time-dependent mass-transfer rate as estimated with the Fick-model was required for an adequate description of the experimental data as also observed with ZL column experiments. Hence, for simulation of complete loading and unloading cycles, the model making use of Fickian diffusion can be applied, whereas the Linear Driving Force model is inapplicable due to failure in simulating the regeneration.

\subsection{Simulations}

Simulations were performed with the model making use of Fickian diffusion to determine the mass-transfer zone length and to study the evolution of the axial and radial concentration gradients. These results help in explaining the observed effects like the great impact of the flow rate on the width of the breakthrough profile and mass-transfer enhancement during regeneration. In the experimental section it was established that the mass transfer zone length (the part of the column where $0.99>C / C_{\text {Feed }}>0.01$ ) was larger than the column length of $28 \mathrm{~cm}$. For this reason simulations were performed using a significantly longer column of $2 \mathrm{~m}$ that would fit the mass-transfer zone and allows to study the effect of flow rate on the mass-transfer zone length in a larger range of flow rates.

\subsubsection{The loading cycle}

In the simulation, during the loading cycle, the column that is initially filled with pure water was from $t=0$ continuously fed with a $500 \mathrm{ppm} \mathrm{CP}$ solution at varying flow rates. The length of the mass-transfer zone (MTZ) was calculated at each time and is plotted in Fig. 11 as function of the breakthrough time, defined as the ratio of time and the time until breakthrough.

In Fig. 11 it can be observed that initially the lengths of the MTZ do not strongly vary with flow rate, as time progresses the differences between the lengths of the MTZ increase. With a flow rate of 2.5 and $1 \mathrm{~mL} / \mathrm{min}$, the length of the MTZ hardly increases, while at a flow rate of $5 \mathrm{~mL} / \mathrm{min}$ the MTZ continuously increases until the breakthrough. The continuous increase of the MTZ at $5 \mathrm{~mL} / \mathrm{min}$ is due to the shorter residence time in the column, also explaining the greater differences between the model and experimental results previously determined. The MTZ length varied between $0.4 \mathrm{~m}$ up to $1.2 \mathrm{~m}$ under the conditions applied in these simulations.

\subsubsection{Regeneration}

The regeneration cycle of the SIR by a pH swing was simulated to estimate the axial concentration gradients in the column and the radial concentration gradients inside the SIR particle. The column was loaded with a $500 \mathrm{ppm}$ CP solution, and the simulation was started with a column where the aqueous phase had a concentration of CP equal to feed concentration and the SIR particles were fully saturated with CP. In Fig. 12, the axial concentration gradients during regeneration are presented, where the regeneration break-

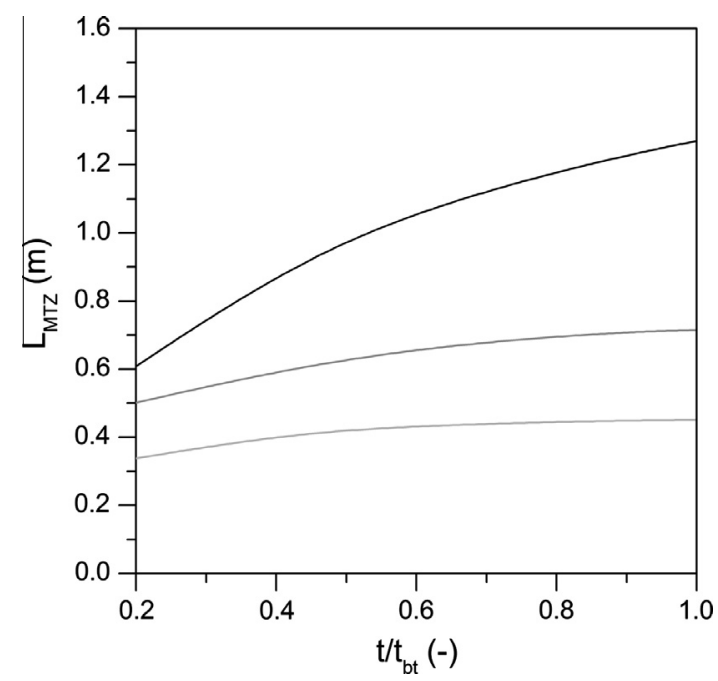

Fig. 11. Length of the mass transfer zone as function of the flow rate. Colors: flow rate of $5 \mathrm{~mL} / \mathrm{min}$ (black), $2.5 \mathrm{~mL} / \mathrm{min}$ (dark grey) and $1 \mathrm{~mL} / \mathrm{min}$ (light grey). (For interpretation of the references to colour in this figure legend, the reader is referred to the web version of this article.)

through time was defined as the time where the outlet concentration was at its maximum.

In Fig. 12 it can be observed that the concentration profile develops as a wave through the column. A maximum concentration is reached, from this maximum the concentration reduces to the original feed concentration. The profile is set by the gradient of the $\mathrm{HCl}$ concentration through the column, as described by the axial dispersion. At a flow rate of $1 \mathrm{~mL} / \mathrm{min}$, a maximum outlet concentration of 7 times the original feed concentration was reached, which is the thermodynamic maximum at these conditions. This corresponds also with the flattened concentration gradient near the exit of the column in Fig. 11, which shows that the aqueous phase composition is in equilibrium with the organic phase composition. At a flow rate of $5 \mathrm{~mL} / \mathrm{min}$ this maximum was not reached, because the residence time in the column was too short and the mass-transfer limits the regeneration. Therefore a maximum concentration of only approximately 5 times the original feed concentration is reached.

In Fig. 13, the radial concentration profiles are presented as it develops inside the SIR. Initially the concentration gradient was

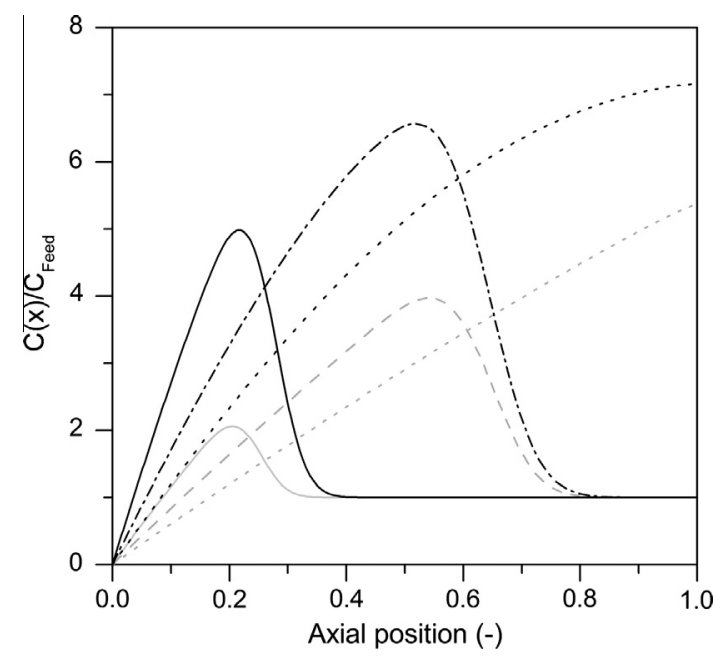

Fig. 12. Axial concentration profile in the column during regeneration at $1 \mathrm{~mL} / \mathrm{min}$ (black) and $5 \mathrm{~mL} / \mathrm{min}$ (light grey) at a regeneration breakthrough time of 0.1 (continuous), 0.5 (dashed) and 1 (dotted). 


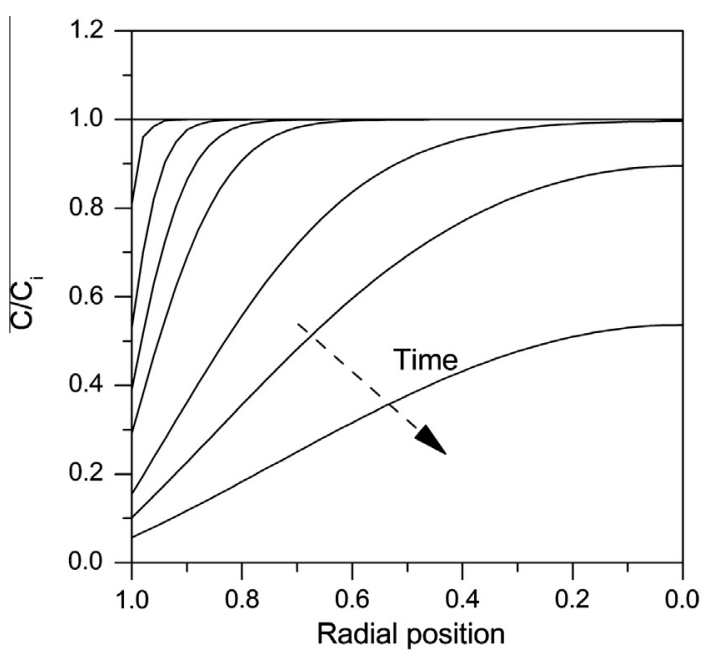

Fig. 13. Radial concentration profiles in the SIR particle during regeneration.

steep. This results in the fastest mass-transfer due to a higher driving force for diffusion. As time progresses the gradient flattens and mass-transfer reduces, these results show a large dependency of mass-transfer with respect to time. Because of this large dependency, the regeneration process could be correctly described by the Fick-model, but not with the LDF-model.

\section{Conclusions}

A solvent impregnated resin (SIR) was developed for the selective removal of 4-cyanopyridine (CP) from an aqueous waste stream containing also acetic acid and succinonitrile. The solvent impregnated resin consisted of Amberlite XAD4 impregnated with a 1:1 mixture (mole basis) of 3,5-dibromo-4-(4,8-dimethylnonyl)phenol and 3,5-dibromo-4-(4,6,6-trimethylheptyl)phenol that had a capacity of $21 \mathrm{~g} \mathrm{CP} / \mathrm{kg}$ SIR at an aqueous feed concentration of $500 \mathrm{ppm} \mathrm{CP}$. The selectivity of the solvent impregnated resin toward CP was above 500. A thermodynamic model was developed, describing the hydrogen bonding interactions between $\mathrm{CP}$ and the solvent. The model was able to describe the equilibrium isotherm with high accuracy. The mass-transfer rates were studied and the diffusion coefficient of $\mathrm{CP}$ in this solvent was estimated at $6.53 \cdot 10^{-13} \mathrm{~m}^{2} \mathrm{~s}^{-1} \pm 2.5 \%$. Validation of the model with fixed-bed column experiments revealed that with a constant diffusion coefficient the data could be described with sufficient accuracy for the loading cycle as well as the regeneration cycle using the Fickmodel, $R^{2}$-values of 0.94 to 0.99 were obtained. The Fick-model was selected over the linear driving force model, because regeneration of the SIR could not be described accurately by the linear driving force model due to underestimation of the mass-transfer rates. The axial concentration gradients were simulated and it was found that mass-transfer is strongly limiting and the masstransfer zone lengths varied from $0.4 \mathrm{~m}$ to $1.5 \mathrm{~m}$, depending on the superficial velocity through the bed.

\section{Acknowledgement}

This was an ISPT (institute for sustainable process technology) project.

\section{Appendix A}

2,6-Dibromo-4-hydroxybenzaldehyde (5) was prepared in two steps from 3,5 dibromophenol $\mathbf{3}$ according to a procedure as described by Dabrowski [33]. 1-Bromo-3,5,5-trimethylhexane 11
[34] and 1-Bromo-3,7-dimethyloctane 12 [35] were prepared according to literature procedures. 2,6-Dibromo-4-methoxybenzaldehyde (6). To 2,6-dibromo-4-hydroxybenzaldehyde (70 g, $0.25 \mathrm{~mol})$ in acetone $(600 \mathrm{~mL})$ was added potassium carbonate $(51.8 \mathrm{~g}, 0.38 \mathrm{~mol})$ and dimethylsulfate $(47.3 \mathrm{~g}, 0.38 \mathrm{~mol})$. The mixture was stirred overnight at room temperature. The color of the mixture turns from pink to white. The acetone was removed by rotary evaporation at $50^{\circ} \mathrm{C}$ under reduced pressure. Water $(200 \mathrm{~mL}$ ) was added to the residue and the mixture was stirred for $15 \mathrm{~min}$ and filtered. The pale yellow solid was washed with water. The solid was dried in vacuo and stripped with toluene yielding a pale yellow solid (73 $\mathrm{g}, 0.248 \mathrm{~mol}, 99 \%) .{ }^{1} \mathrm{H}$ NMR (DMSO-d ${ }_{6}$ ): $\partial 10.06(\mathrm{~s}, 1 \mathrm{H}), 7.39(\mathrm{~s}, 2 \mathrm{H}), 3.87(\mathrm{~s}, 3 \mathrm{H}) \cdot{ }^{13} \mathrm{C}$ NMR (75 MHz, $\mathrm{CDCl}_{3}$ ): $190.34(\mathrm{CH}), 162.91$ (C), 127.22 (C), 124.79 (C), $119.93(\mathrm{CH}), 56.39\left(\mathrm{CH}_{3}\right) .{ }^{13} \mathrm{C}$ NMR data identical to [33]. A similar reaction has been performed on $0.1 \mathrm{~mol}$ scale. The product was obtained in $95 \%$ isolated yield.

1-(2,6-Dibromo-4-methoxyphenyl)-4,6,6-trimethylheptan-1-ol (7a). 1-Bromo-3,5,5-trimethylhexane 11 (62.15 g, $0.3 \mathrm{~mol})$ was added portionwise to a suspension of Magnesium $(7.44 \mathrm{~g}$, $0.3 \mathrm{~mol})$ in $\mathrm{Et}_{2} \mathrm{O}(100 \mathrm{~mL})$ containing a few drops of 1,2-dibromoethane. After start of the Grignard the remainder of the bromide was added dropwise at such a rate as to maintain reflux. After addition the solution was heated at reflux for an additional $30 \mathrm{~min}$ and after cooling added dropwise to a solution of 2,6-dibromo-4-methoxybenzaldehyde $(45 \mathrm{~g}, 0.15 \mathrm{~mol})$ in THF (600 mL) keeping $T<27^{\circ} \mathrm{C}$ using a waterbath. The solution was allowed to stir at RT for $3 \mathrm{~h}$ and poured into $1 \mathrm{~N} \mathrm{HCl}(500 \mathrm{~mL})$. After separation of the layers, the water phase was extracted with TBME $(2 \times 250 \mathrm{~mL})$. The combined organic layers were washed with brine $(150 \mathrm{~mL})$, dried $\left(\mathrm{Na}_{2} \mathrm{SO}_{4}\right)$, filtered and concentrated in vacuo to give $68 \mathrm{~g}$ of crude oil. Heptanes $(100 \mathrm{~mL})$ were added to the oily residue and a precipitate ((2,6-dibromo-4-methoxyphenyl)methanol, $12.4 \mathrm{~g}$ ) formed which was filtered off. The target material dissolved in heptanes was subjected to column chromatography (silicagel, $300 \mathrm{~g}$ ) and eluted with heptanes to remove alkane cross coupling by-products and subsequently with heptanes/EtOAc 95/5 to $90 / 10$ to give $7 \mathrm{a}$ (36 $\mathrm{g}$ in two fractions, $21 \mathrm{~g}$ pure and $15 \mathrm{~g}$ less pure, containing $10 \%$ of unreacted 1-Bromo-3,5,5-trimethylhexane 11. The yellow oily residues were combined $(36 \mathrm{~g}, 85.2 \mathrm{mmol}$, 57\%). ${ }^{1} \mathrm{H}$ NMR $\left(\mathrm{CDCl}_{3}\right)$ : $27.10(\mathrm{~s}, 2 \mathrm{H}), 5.28(\mathrm{~m}, 1 \mathrm{H}), 3.78(\mathrm{~s}, 3 \mathrm{H})$, $2.74(\mathrm{dd}, 1 \mathrm{H}), 1.97(\mathrm{~m}, 2 \mathrm{H}), 1.58-1.38(\mathrm{~m}, 1 \mathrm{H}), 1.26-1.18(\mathrm{~m}$, $2 \mathrm{H}), 1.08-1.00(\mathrm{~m}, 2 \mathrm{H}), 0.93-0.76(\mathrm{~m}, 12 \mathrm{H})$.

1-(2,6-dibromo-4-methoxyphenyl)-4,8-dimethylnonan-1-ol (7b). This compound was synthesized from 1-Bromo-3,7-dimethyloctane analogous to compound 7a. The material dissolved in heptanes was subjected to column chromatography (silicagel, $300 \mathrm{~g}$ ) and eluted with heptanes to remove alkane cross coupling byproducts and subsequently with heptanes/EtOAc 95/5 to 90/10 to give $\mathbf{7 b}$ (33.7 g in two fractions, $15.2 \mathrm{~g}$ pure and $22 \mathrm{~g}$ less pure, containing $10 \%$ of 1 -(2-bromo-4-methoxyphenyl)-4,8-dimethylnonan1 -ol. The yellow oily residues were combined $(33.7 \mathrm{~g}, 85.2 \mathrm{mmol}$, 57\%). ${ }^{1} \mathrm{H}$ NMR $\left(\mathrm{CDCl}_{3}\right)$ : $27.12(\mathrm{~s}, 2 \mathrm{H}), 5.30(\mathrm{~m}, 1 \mathrm{H}), 3.80(\mathrm{~s}, 3 \mathrm{H})$, $2.76(\mathrm{~d}, 1 \mathrm{H}, \mathrm{J}=9.8 \mathrm{~Hz}), 2.1-1.9(\mathrm{~m}, 2 \mathrm{H}), 1.59-1.04(\mathrm{~m}, 10 \mathrm{H}), 0.95$ $(\mathrm{m}, 9 \mathrm{H})$

1,3-Dibromo-5-methoxy-2-(4,6,6-trimethylheptyl)benzene (8a). 11-(2,6-Dibromo-4-methoxyphenyl)-4,6,6-trimethylheptan-1-ol $7 \mathrm{a}(36 \mathrm{~g}, 85.2 \mathrm{mmol})$ was dissolved in DCM (500 $\mathrm{mL})$ and cooled to $0{ }^{\circ} \mathrm{C}$. Triethylsilane $(38.5 \mathrm{~mL}, 241 \mathrm{mmol})$ was added at once followed by dropwise addition of $\mathrm{BF}_{3} . \mathrm{Et}_{2} \mathrm{O}(15.2 \mathrm{~mL}, 120.4 \mathrm{mmol})$ keeping $T<5{ }^{\circ} \mathrm{C}$ and the solution was stirred at this temperature for $1.5 \mathrm{~h}$. The solution was treated with sat. $\mathrm{NaHCO}_{3}(500 \mathrm{~mL})$ and diluted further with some DCM and stirred for $30 \mathrm{~min}$ until gas evolution ceased. The layers were separated and the organic phase was washed with brine, dried $\left(\mathrm{Na}_{2} \mathrm{SO}_{4}\right)$, filtered and concentrated in vacuo to give $\mathbf{8 a}(34.2 \mathrm{~g}, 99 \%)$ which was isolated as a 
yellow oil. The product was used in the next step without further purification. ${ }^{1} \mathrm{H}$ NMR $\left(300 \mathrm{MHz}, \mathrm{CDCl}_{3}\right)$ : a $7.10(\mathrm{~s}, 2 \mathrm{H}), 3.78(\mathrm{~s}$, $3 \mathrm{H}), 2.87(\mathrm{~m}, 2 \mathrm{H}), 1.6-0.86(\mathrm{~m}, 19 \mathrm{H}) .{ }^{13} \mathrm{C} \mathrm{NMR}\left(75 \mathrm{MHz}, \mathrm{CDCl}_{3}\right)$ : $158.20(\mathrm{C}), 133.75(\mathrm{C}), 124.96(\mathrm{C}), 118.31(\mathrm{CH}), 55.89\left(\mathrm{CH}_{3}\right)$, $51.44\left(\mathrm{CH}_{2}\right), 39.63\left(\mathrm{CH}_{2}\right), 36.58\left(\mathrm{CH}_{2}\right), 31.32\left(\mathrm{CH}_{2}\right), 30.37\left(\mathrm{CH}_{3}\right)$, $29.34(\mathrm{CH}), 26.46\left(\mathrm{CH}_{2}\right), 22.86\left(\mathrm{CH}_{3}\right)$; GC-MS: $\mathrm{m} / \mathrm{z} 404,406.01$, 408. MS calculated for $\mathrm{C}_{17} \mathrm{H}_{26} \mathrm{Br}_{2} \mathrm{O}: 404.04 ; 406.03 ; 408.03$.

1,3-Dibromo-2-(4,8-dimethylnonyl)-5-methoxybenzene (8b). This compound was synthesized analogous to 8a from 1-(2,6dibromo-4-methoxyphenyl)-4,8-dimethylnonan-1-ol 7b. The product ( $34.2 \mathrm{~g}$, quant.) was isolated as a yellow oil and used in the next step without purification. ${ }^{1} \mathrm{H} \mathrm{NMR}\left(\mathrm{CDCl}_{3}\right)$ a $7.07(\mathrm{~s}, 2 \mathrm{H})$, $3.76(\mathrm{~s}, 3 \mathrm{H}), 2.85(\mathrm{~m}, 2 \mathrm{H}), 1.6-1.1(3 \mathrm{xm}, 12 \mathrm{H}), 0.87(2 \mathrm{xd}, 9 \mathrm{H}) .{ }^{13} \mathrm{C}$ NMR (75 MHz, $\mathrm{CDCl}_{3}$ ): 158.20 (C), 133.78 (C), 124.94 (C), 118.32 $(\mathrm{CH}), 55.92\left(\mathrm{CH}_{3}\right), 39.60\left(\mathrm{CH}_{2}\right), 37.38\left(\mathrm{CH}_{2}\right), 37.12\left(\mathrm{CH}_{2}\right), 36.55$ $\left(\mathrm{CH}_{2}\right), 32.69(\mathrm{CH}), 28.21(\mathrm{CH}), 26.26\left(\mathrm{CH}_{2}\right), 24.96\left(\mathrm{CH}_{2}\right), 22.97$ $\left(\mathrm{CH}_{3}\right), 22.88\left(\mathrm{CH}_{3}\right), 19.91\left(\mathrm{CH}_{3}\right)$. GC-MS: $\mathrm{m} / \mathrm{z} 418 ; 420.1 ; 422$. MS calculated for $\mathrm{C}_{18} \mathrm{H}_{28} \mathrm{Br}_{2} \mathrm{O}: 418.05 ; 420.05 ; 422.05$.

1-Iodo-3,5,5-trimethylhexane (9). 1-Chloro-3,5,5-trimethylhexane $(20 \mathrm{~g}, 0.11 \mathrm{~mol})$ was dissolved in acetone $(100 \mathrm{~mL})$ and sodium iodide $(17.0 \mathrm{~g}, 0.12 \mathrm{~mol})$ was added. The mixture was refluxed for $24 \mathrm{~h}$ but the reaction was still incomplete. Therefore additional sodium iodide $(17.0 \mathrm{~g}, 0.11 \mathrm{~mol}$ ) was added and the reaction mixture refluxed for another $24 \mathrm{~h}$. The salts were filtered off and extracted with acetone. The acetone was evaporated. Water $(100 \mathrm{~mL})$ and TBME $(200 \mathrm{~mL})$ were added to the residue. After separation of the layers, the TBME layer was washed with water $(100 \mathrm{~mL})$ and brine $(100 \mathrm{~mL})$. After drying $\left(\mathrm{Na}_{2} \mathrm{SO}_{4}\right)$, the organic phase was concentrated in vacuo to give 9 (27.2 g, $0.1 \mathrm{~mol}, 90 \%)$ as an oil. ${ }^{1} \mathrm{H}$ NMR $\left(\mathrm{CDCl}_{3}\right)$ a $3.23-3.11(\mathrm{~m}, 2 \mathrm{H}), 1.88-1.82(\mathrm{~m}$, $1 \mathrm{H}), 1.68-1.59(\mathrm{~m}, 2 \mathrm{H}), 1.22-1.05(\mathrm{~m}, 2 \mathrm{H}), 0.92-0.80(\mathrm{~m}, 12 \mathrm{H})$. ${ }^{13} \mathrm{C}$ NMR (75 MHz, $\left.\mathrm{CDCl}_{3}\right): 50.89\left(\mathrm{CH}_{2}\right), 43.42\left(\mathrm{CH}_{2}\right), 31.42(\mathrm{C})$, $30.60(\mathrm{CH}), 30.29\left(\mathrm{CH}_{3}\right), 22.05\left(\mathrm{CH}_{3}\right), 5.60\left(\mathrm{CH}_{2}\right)$. GC-MS: purity 96.6\%; $\mathrm{m} / z$ 254.0. MS calculated for $\mathrm{C}_{9} \mathrm{H}_{19} \mathrm{I}: 254.05$.

1-Iodo-3,7-dimethyloctane (10). This compound was synthesized analogous to 9 from 1-Chloro-3,7-dimethyloctane. Target material $10(27.2 \mathrm{~g}, 89 \%)$ was isolated as an oil. ${ }^{1} \mathrm{H} \mathrm{NMR}\left(\mathrm{CDCl}_{3}\right)$ o 3.29-3.12 $(\mathrm{m}, 2 \mathrm{H}), 1.93-1.81(\mathrm{~m}, 1 \mathrm{H}), 1.70-1.48(\mathrm{~m}, 3 \mathrm{H}), 1.33-1.10(\mathrm{~m}, 6 \mathrm{H})$, 0.88-0.90 (m, 9H). ${ }^{13} \mathrm{C}$ NMR (75 MHz, $\left.\mathrm{CDCl}_{3}\right): 41.21\left(\mathrm{CH}_{2}\right), 39.42$ $\left(\mathrm{CH}_{2}\right), 36.72\left(\mathrm{CH}_{2}\right), 34.11(\mathrm{CH}), 28.18(\mathrm{CH}), 24.78\left(\mathrm{CH}_{2}\right), 22.96$ $\left(\mathrm{CH}_{3}\right), 22.86\left(\mathrm{CH}_{3}\right), 19.12\left(\mathrm{CH}_{3}\right), 5.77\left(\mathrm{CH}_{2}\right)$. Analytical data is identical to published data [36]. GC-MS: purity 99.3\%; $\mathrm{m} / z$ 268.0. MS calculated for $\mathrm{C}_{10} \mathrm{H}_{21} \mathrm{I}$ : 268.07 .

3,5-Dibromo-4-(4,6,6-trimethylheptyl)phenol (1). 1,3-Dibromo-5methoxy-2-(4,6,6-trimethylheptyl)benzene 8a (34.0 g, $83.7 \mathrm{mmol})$ was dissolved in DCM $(270 \mathrm{~mL})$ and $\mathrm{BBr}_{3}(100 \mathrm{~mL}, 1 \mathrm{M}$ in DCM, $100 \mathrm{mmol}$ ) was added. The reaction was not complete after $24 \mathrm{~h}$ of stirring at room temperature. Therefore additional $\mathrm{BBr}_{3}$ ( $40 \mathrm{~mL}, 1 \mathrm{M}$ in DCM, $40 \mathrm{mmol}$ ) was added. The reaction was complete after 6 additional hours of stirring. The solution was treated carefully with $\mathrm{H}_{2} \mathrm{O}(300 \mathrm{~mL})$ and stirred for $30 \mathrm{~min}$. The layers were separated and the DCM layer was washed with sat. $\mathrm{NaHCO}_{3}$ $(300 \mathrm{~mL})$, brine $(150 \mathrm{~mL})$, dried $\left(\mathrm{Na}_{2} \mathrm{SO}_{4}\right)$, filtered and concentrated in vacuo to give $34 \mathrm{~g}$ of crude oil. The material was subjected to column chromatography with heptanes/EtOAc 9/1 to give $\mathbf{1}$ $(29.1 \mathrm{~g}, 74.2 \mathrm{mmol}, 89 \%)$ which was isolated as an orange oil. HPLC-MS showed a purity of $98 \%(215 \mathrm{~nm})$ and $97 \%(288 \mathrm{~nm}) .{ }^{1} \mathrm{H}$ NMR (300 MHz, $\mathrm{CDCl}_{3}$ ): $\partial 7.03(\mathrm{~s}, 2 \mathrm{H}), 4.87$ (br s, $\left.1 \mathrm{H}\right), 2.83(\mathrm{~m}$, 2H), 1.6-0.86 (m, chain, $19 \mathrm{H}) .{ }^{13} \mathrm{C}$ NMR $\left(75 \mathrm{MHz} \mathrm{CDCl}_{3}\right): 154.08$ (C), $134.15(\mathrm{C}), 124.98(\mathrm{C}), 119.76(\mathrm{CH}), 51.44\left(\mathrm{CH}_{2}\right), 39.63\left(\mathrm{CH}_{2}\right)$, $36.54\left(\mathrm{CH}_{2}\right), 31.32\left(\mathrm{CH}_{2}\right), 30.39\left(\mathrm{CH}_{3}\right), 29.33(\mathrm{CH}), 26.42\left(\mathrm{CH}_{2}\right)$, $22.88\left(\mathrm{CH}_{3}\right)$. HPLC-MS: purity: $98.00 \%$ at $215 \mathrm{~nm}, 97.08 \%$ at $288 \mathrm{~nm}$. Column: Zorbax SB Aq $(2.10 \times 50 \mathrm{~mm} ; 1.7 \mu \mathrm{m}, 1200 \mathrm{bar})$; Mobile phase: Solution A : Solution $B=50: 50 \quad(0 \mathrm{~min}) \rightarrow$ $(1.5 \mathrm{~min}) \rightarrow 0: 100(1.5 \mathrm{~min})$; Flow: $0.60 \mathrm{ml} / \mathrm{min}$; UV Detection: $210 \mathrm{~nm}$ and $288 \mathrm{~nm}$; Injection volume: $0.2 \mu \mathrm{L}$; Mass Detection:
API ES positive and negative; solution A: $9.65 \mathrm{~g}$ ammonium acetate; $2250 \mathrm{~mL} \mathrm{H}_{2} \mathrm{O} ; 150 \mathrm{~mL}$ methanol; $100 \mathrm{~mL}$ acetonitrile; solution $\mathrm{B}$ : $9.65 \mathrm{~g}$ ammonium acetate; $250 \mathrm{~mL} \mathrm{H}_{2} \mathrm{O} ; 1350 \mathrm{~mL}$ methanol; $900 \mathrm{~mL}$ acetonitrile. MS calculated for $\mathrm{C}_{16} \mathrm{H}_{24} \mathrm{Br}_{2} \mathrm{O}$ : 390.02; MS (API ES Neg): $m / z 389.00(\mathrm{M}-1)$.

3,5-Dibromo-4-(4,8-dimethylnonyl)phenol (2). This compound was synthesized analogous to $\mathbf{1}$ from 1,3-dibromo-2-(4,8-dimethylnonyl)-5-methoxybenzene $\mathbf{8 b}$. The material was subjected to column chromatography with heptanes/EtOAc 9/1 to give 2 $(28.3 \mathrm{~g}, 69.6 \mathrm{mmol}, 86 \%)$ which was isolated as an orange oil (25.8 g, $63.5 \mathrm{mmol}, 78 \%) .{ }^{1} \mathrm{H}$ NMR $\left(300 \mathrm{MHz}, \mathrm{CDCl}_{3}\right.$ ): o 7.03 (s, $2 \mathrm{H}), 4.80$ (br s, 1H), 2.84 (m, 2H), 1.60-1.06 (m, 14H), 0.87 (2xd, 9H). HPLC-MS: purity: $96.4 \%$ at $215 \mathrm{~nm}, 94.7 \%$ at $288 \mathrm{~nm}$. Column: Zorbax SB C18 $(2.10 \times 50 \mathrm{~mm}$; $1.8 \mu \mathrm{m}$, RRHD 1200 bar $)$; Mobile phase: Solution A:Solution $B=20: 80(0 \mathrm{~min}) \rightarrow(1 \mathrm{~min}) \rightarrow 0: 100$ (3 min); Flow: $1.0 \mathrm{ml} / \mathrm{min}$; UV Detection: $215 \mathrm{~nm}$ and $288 \mathrm{~nm}$; Injection volume: $0.2 \mu \mathrm{L}$; Mass Detection: API ES positive and negative; solution A: $9.65 \mathrm{~g}$ ammonium acetate; $2250 \mathrm{~mL} \mathrm{H}_{2} \mathrm{O} ; 150 \mathrm{~mL}$ methanol; $100 \mathrm{~mL}$ acetonitrile; solution $\mathrm{B}$ : $9.65 \mathrm{~g}$ ammonium acetate; $250 \mathrm{~mL} \mathrm{H} \mathrm{H}_{2} \mathrm{O} ; 1350 \mathrm{~mL}$ methanol; $900 \mathrm{~mL}$ acetonitrile. MS calculated for $\mathrm{C}_{17} \mathrm{H}_{26} \mathrm{Br}_{2} \mathrm{O}$ : 404.04; MS (API ES Neg): $m / z 402.95$ (M-1). A small impurity which was identified as 3-Bromo-4(4,8-dimethylnonyl)phenol was detected $(2.9 \%$ at $215 \mathrm{~nm}$ and $4.8 \%$ at $288 \mathrm{~nm}$; MS calculated for $\mathrm{C}_{17} \mathrm{H}_{27} \mathrm{BrO}$ : 326.12 , MS (API ES Neg): $m / z 325.10(\mathrm{M}-1))$.

\section{Appendix B. Supplementary material}

Supplementary data associated with this article can be found, in the online version, at http://dx.doi.org/10.1016/j.reactfunctpolym. 2014.11.007.

\section{References}

[1] S.W. Wang, A.L. Hines, D.S. Farrier, J. Chem. Eng. Data 24 (1979) 345-347.

[2] S. Kumar, K.L. Wasewar, B.V. Babu, Chem. Eng. Technol. 31 (2008) 1584-1590.

[3] A. Warshawsky, J.L. Cortina, M. Aguilar, K. Jerabek, New developments in solvent impregnated resins. An overview, in: M. Cox, M. Hidalog, M. Valiente (Eds.), Solvent Extraction for the 21st Century, Proceedings of ISEC ' 99 , Barcelona, Spain, July 11-16, 1999, 2001, pp. 1267-1272.

[4] Y. Bai, Q. Sun, R. Xing, D. Wen, X. Tang, J. Hazard. Mater. 181 (2010) 916-922.

[5] R.R. Chaudhary, P. Kumar, S. Chand, J. Sci. Ind. Res. 65 (2006) 757-759.

[6] K.V. Padoley, S.N. Mudliar, S.K. Banerjee, S.C. Deshmukh, R.A. Pandey, Chem. Eng. J. 166 (2010) 1-9.

[7] J.M. Wyatt, C.J. Knowles, Biodegradation 6 (1995) 93-107.

[8] N. Kabay, J.L. Cortina, A. Trochimczuk, M. Streat, React. Funct. Polym. 70 (2010) 484-496.

[9] C. Van Den Berg, F. Boon, M. Roelands, P. Bussmann, E. Goetheer, D. Verdoes, L. Van Der Wielen, Sep. Purif. Technol. 74 (2010) 318-328.

[10] X. Gong, Y. Lu, G. Luo, Sep. Purif. Technol. 69 (2009) 71-77.

[11] K. Babic, L.G.J. Van Der Ham, A.B. de Haan, Adsorption 14 (2008) 357-366.

[12] B. Burghoff, E.L.V. Goetheer, A.B. de Haan, J. Ind. Eng. Chem. 68 (2008) 13141324.

[13] B. Burghoff, J. Sousa Marques, B.M. van Lankvelt, A.B. de Haan, React. Funct. Polym. 70 (2010) 41-47.

[14] R.S. Juang, H.L. Chang, Ind. Eng. Chem. Res. 34 (1995) 1294-1301.

[15] A. Kostova, I. Tsibranska, H.J. Bart, Solv. Extr. Ion Exch. 25 (2007) 127-145.

[16] M.O. Ruiz, J.L. Cabezas, I. Escudero, J. Coca, Chem. Eng. Res. Des. 80 (2002) 537542.

[17] M. Traving, Chem. Eng. Technol. 25 (2002) 997-1003.

[18] D. Muraviev, L. Ghantous, M. Valiente, React. Funct. Polym. 38 (1998) 259-268.

[19] J. Bokhove, B. Schuur, A.B. Haan, Sep. Purif. Technol. 98 (2012) 410-418.

[20] D. Varhanickova, W.Y. Shiu, D. Mackay, J. Chem. Eng. Data 40 (1995) 448-451.

[21] J. Bokhove, B. Schuur, A.B. Haan, React. Funct. Polym. 73 (2013) 595-605.

[22] C. Laurence, J.-F. Gal, Thermodynamic and spectroscopic scales of hydrogenbond, in: C. Laurence, J.-F. Gal (Eds.), Lewis Basicity and Affinity Scales: Data and Measurement, John Wiley \& Sons Ltd., Chichester, 2010.

[23] J. Bokhove, B. Schuur, A.B. Haan, Chem. Eng. Sci. 98 (2012) 410-418.

[24] R.S. Juang, T.C. Chou, J. Chem. Eng. Jpn. 29 (1996) 146-151.

[25] B. Burghoff, E. Zondervan, A.B. de Haan, React. Funct. Polym. 69 (2009) $264-$ 271.

[26] J.D. Seader, E.J. Henley, Adsorption, ion exchange, and chromatography, in: F. Welter, P. McFadden (Eds.), Separation Process Principles, John Wiley \& Sons Inc., Hoboken, 2006, pp. 548-620. 
[27] R.B. Bird, W.E. Stewart, E.N. Lightfoot, Transport Phenomena, John Wiley \& Sons, 2006.

[28] R. Krishna, J.A. Wesselingh, Chem. Eng. Sci. 52 (1997) 861-911.

[29] J. Bokhove, B. Schuur, A.B. Haan, Solvent impregnated resins (SIRS) for the trace removal of aromatic nitrogen containing compounds from wastewater streams, in: F.L. Valenzuela, B.A. Moyer (Eds.), 19th International Solvent Extraction Conference, Gecamin Ltda., Santiago, 2012, Article 151.

[30] S.F. Chung, C.Y. Wen, AlChE J. 14 (1968) 857-866.

[31] J. Dunnewijk, H. Bosch, A.B. de Haan, Chem. Eng. Sci. 61 (2006) 4813-4826.
[32] N. Schouten, L.G.J. Van Der Ham, G.J.W. Euverink, A.B. de Haan, Sep. Purif. Technol. 68 (2009) 199-207.

[33] M. Dąbrowski, J. Kubicka, S. Luliński, J. Serwatowsk, Tetrahedron Lett. 46 (2005) 4175-4178.

[34] J.E. Raymond, A. Bhaskar, T. Goodson III, N. Makiuchi, K. Ogawa, Y. Kobuke, J. Am. Chem. Soc. 130 (2008) 17212-17213.

[35] R. Kannan, G.S. He, T.-C. Lin, P.N. Prasad, R.A. Vaia, L.-S. Tan, Chem. Mater. 16 (2004) 185-194.

[36] For NMR data see: WO2004007475A1 C.Y. Chen, S. Nagumo, H. Akita, Chem. Pharm. Bull. 44 (11) (1996) 2153-2156. 